UNIVERSIDADE DE SÃO PAULO

Escola de Engenharia de São Carlos

Faculdade de Medicina de Ribeirão Preto

Instituto de Química de São Carlos

\title{
ESTUDO DOS EFEITOS DA ORIENTAÇÃO DAS \\ FIBRAS DE COLÁGENO NAS PROPRIEDADES MECÂNICAS DE FLEXÃO E DE IMPACTO DOS OSSOS
}

Adriano de Jesus Holanda

Ribeirão Preto

1999 


\section{ESTUDO DOS EFEITOS DA ORIENTAÇÃO DAS FIBRAS DE COLÁGENO NAS PROPRIEDADES MECÂNICAS DE FLEXÃO E DE IMPACTO DOS OSSOS}

Adriano de Jesus Holanda

Dissertação apresentada à Área de
Bioengenharia Interunidades -
Faculdade de Medicina de
Ribeirão Preto/Escola de
Engenharia de São Carlos/Instituto
de Química de São Carlos,
Universidade de São Paulo para
obtenção do título de Mestre em
Bioengenharia.

Orientador: Prof. Dr. José B. Volpon

Ribeirão Preto

1999 
Este trabalho contou com o apoio financeiro da FAPESP (Fundação de Amparo à Pesquisa do Estado de São Paulo). 


\section{A osmeuspais $F$ rancisco e $R$ osa, $a$ $G$ islaineea toda a minha família, pelo incentivo e apoio no decorrer desta pesquisa.}




\section{AGRADECIMENTOS}

Ao professor José B. Volpon, pelos ensinamentos, incentivo, orientação e ajuda fundamentais para o desenvolvimento deste trabalho e do aluno;

Ao Doutor Antônio C. Shimano pela amizade, dedicação e valiosos ensinamentos que ajudaram na formação não só do trabalho, como também da pessoa que o desenvolveu;

Ao Prof. Dr. José B. P. Paulin, pela acolhida no laboratório;

Ao Prof. Dr. João Kajiwara, pela ajuda técnica na parte de microscopia e aquisição das imagens;

Ao Prof. Dr. Homero Rodrigues, pelo incentivo e ajuda iniciais na parte histológica; Ao aluno Luiz Carlos, pela amizade e ajuda durante a realização desta pesquisa; Ao meu irmão Rodrigo, pela grande ajuda na obtenção das imagens;

Ao aluno Marcos Shimano, pela confecção de alguns desenhos que fazem parte desta dissertação;

Aos funcionários do laboratório: Eng. Moro, Francisco, Luiz Henrique, Terezinha e Sônia, pela amizade e ajuda;

Aos amigos de mestrado Renato, Cláudio, Luciane, Ricardo, Flávio, Rita, Eloísa, Andréa, Cláudia e Vitor, pelo apoio e amizade;

A todos, meus sinceros agradecimentos! 


\section{SUMÁRIO』}

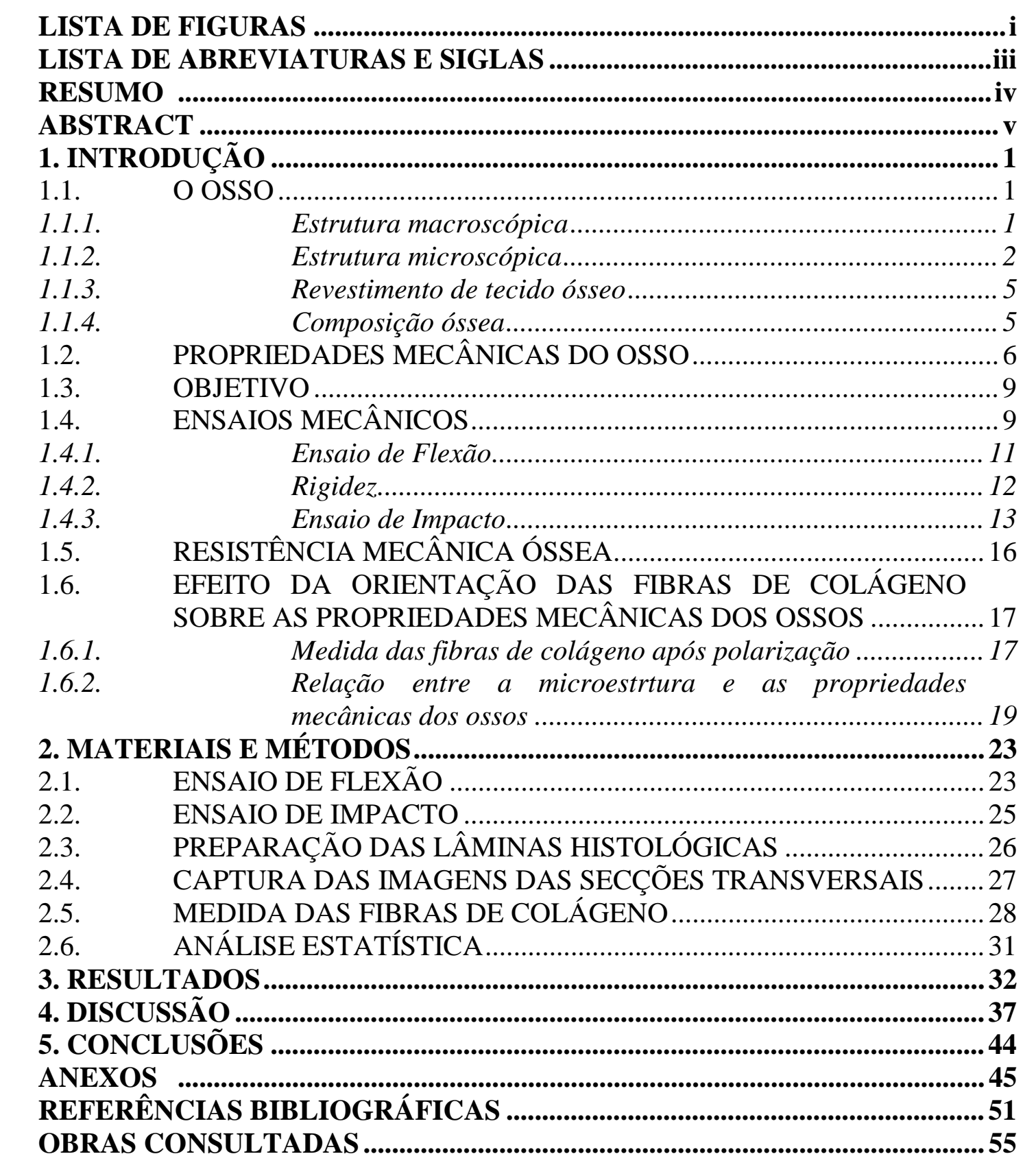

${ }^{1}$ Formato produzido segundo as diretrizes para elaboração de dissertações e teses da EESC - USP. 


\section{LISTA DE FIGURAS}

FIGURA 01 - DIFERENÇAS ENTRE OSSO CORTICAL E ESPONJOSO. ….............................................. 2

FIGURA 02 - ESTRUTURA DA DIÁFISE DO OSSO CORTICAL. (FONTE: CATÁLOGO DA NOVARTIS).......... 4

FIGURA 03 - DIFERENTES CONFIGURAÇÕES DE CURVAS TENSÃO X DEFORMAÇÃO DEPENDENTES DA

VELOCIDADE DE CARREGAMENTO (FONTE: EINHORN, 1996)...............................

FIGURA 04 - OS TRÊS TIPOS BÁSICOS DE TENSÃO: TRAÇ̃̃O, COMPRESSÃO E CISALHAMENTO (FONTE:

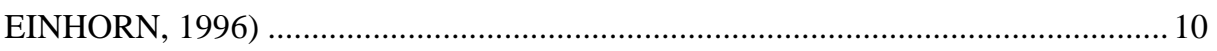

FIGURA 05 - CONFIGURAÇÃO DO ENSAIO DE FLEXÃO. ................................................................... 12

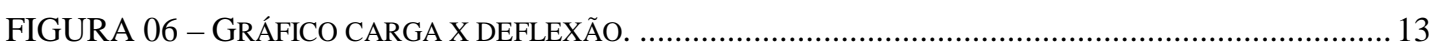

FIGURA 07 - CURSO DO PÊNDULO DA MÁQUINA DE IMPACTO (FONTE: HORATH, 1995),.................. 16

FIGURA 08 - ÓSTEONS CLARO (C), ESCURO (E) E INTERMEDIÁRIO (I) OBTIDOS DE UMA SECÇÃO

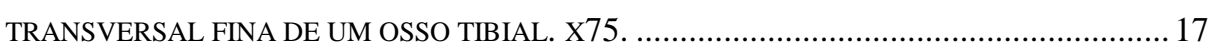

FIGURA 09 - MODELO DE ASCENZI E BONUCCI (1968) DOS TRÊS TIPOS DE ÓSTEONS DE SECÇÃO

TRANSVERSAL SOB POLARIZAÇÃO COM DIAGRAMAS ILUSTRANDO A ORIENTAÇ̃̃̃O DO

FEIXE DE FIBRAS EM LAMELAS SUCESSIVAS. ..................................................... 18

FIGURA 10 - COLOCAÇÃO DO FÊMUR NO ENSAIO DE FLEXÃO..........................................................2

FIGURA 11 - MÁQUINA DE IMPACTO PSD 15/50 UTILIZADA NO ENSAIO DE IMPACTO......................25

FIGURA 12 - COLOCAÇÃO DO FÊMUR NO SUPORTE DE ENSAIO.................................................. 26

FIGURA 13 - CORTES DE SECÇÕES TRANSVERSAIS NOS FÊMURES ENSAIADO....................................2

FIGURA 14 - SISTEMA UTILIZADO PARA AQUISIÇÃO DAS IMAGENS DAS LÂMINAS HISTOLÓGICAS. ......28

FIGURA 15 - IMAGEM DE PARTE DA SECÇÃO TRANSVERSAL CAPTURADA ANTES DA POLARIZAÇ̃̃O....29

FIGURA 16 - SECÇÃO TRANSVERSAL APÓS POLARIZAÇÃO DA LUZ. ..................................................... 29

FIGURA 17 - SECÇÃO TRANSVERSAL APÓS THRESHOLDING E BINARIZAÇÃO. ................................... 30

FIGURA 18 - CÁLCULO DA ÁREA TOTAL OCUPADA PELA SECÇÃO ÓSSEA............................................ 30

FIGURA 19 - CURVA CARGA X DEFLEXĨO PARA OS 20 FÊMURES ENSAIADOS.................................. 32

FIGURA 20 - COMPARAÇÃO DAS TENACIDADES OBTIDAS NOS DOIS ENSAIOS. .................................. 35 
LISTA DE TABELAS

TABELA 01 - PROPRIEDADES MECÂNICAS DE FLEXÃO. ............................................................ 33

TABELA 02 - ENERGIA ABSORVIDA PELOS FÊMURES NO ENSAIO DE IMPACTO....................................... 34

TABELA 03 - ÁREA RELATIVA OCUPADA PELAS FIBRAS DE COLÁGENO $\left(A_{R F}\right)$ OBTIDAS A PARTIR DAS

SECÇÕES TRANSVERSAIS DOS FÊMURES ENSAIADOS................................................ 34

TABELA 04 - PROPRIEDADES MECÂNICAS E MICROESTRUTUTURAL................................................... 35

TABELA 05 - ÍNDICE DE CORRELAÇÃO LINEAR (R) ENTRE AS PROPRIEDADES MECÂNICAS E A ESTIMATIVA DAS FIBRAS DE COLÁGENO TRANSVERSAIS DAS SECÇÕES ÓSSEAS.............36 


\section{LISTA DE ABREVIATURAS E SIGLAS}

$\begin{array}{ll}\beta & \text { ângulo final (ângulo de subida) } \\ \alpha & \text { ângulo inicial (ângulo de queda) } \\ \text { ABNT - } & \text { Associação Brasileira de Normas Técnicas } \\ A_{R F}- & \text { área relativa ocupada pelas fibras de colágeno } \\ C- & \text { carga } \\ d- & \text { deflexão } \\ \text { def. - } & \text { deflexão } \\ E- & \text { energia potencial inicial do pêndulo } \\ g- & \text { aceleração da gravidade }\left(9,81 \mathrm{~m} / \mathrm{s}^{2}\right) \\ h- & \text { altura de queda do pêndulo } \\ \mathrm{J}- & \text { Joule } \\ \mathrm{kg}- & \text { kilograma } \\ m- & \text { massa do pêndulo } \\ \mathrm{m}- & \text { metro } \\ M- & \text { momento fletor da viga } \\ \mathrm{mm}- & \text { milímetro } \\ \mathrm{N}- & \text { Newton } \\ r- & \text { comprimento do pêndulo } \\ R- & \text { rigidez } \\ \mathrm{s}- & \text { segundo }\end{array}$




\section{RESUMO}

A relação entre as propriedades mecânicas dos ossos obtidas nos ensaios de flexão em três pontos e a orientação das fibras de colágeno foi estudada, bem como a relação entre a energia absorvida nos dois ensaios. Limite máximo, limite proporcional, rigidez, resiliência e tenacidade foram obtidas a partir de ensaio de flexão em três pontos de 20 fêmures esquerdos de coelhos. A energia absorvida (tenacidade) no impacto foi obtida utilizando os 20 fêmures direitos. A orientação das fibras de colágeno foi estimada utilizando a técnica de polarização da luz.

A análise de regressão mostrou que na flexão, rigidez teve correlação positiva $(R=0,43)$ e resisliência, correlação negativa $(R=-0,46)$ com a orientação das fibras de colágeno. A energia absorvida no impacto não apresentou índice de correlação significativo $(\mathrm{p}<0,05)$.

A energia absorvida no ensaio de impacto pelos fêmures foi $523 \%$ maior que a energia absorvida ensaio de flexão.

Palavras-chave: biomecânica; osso; flexão; impacto; colágeno. 
The relationship between the mechanical properties of bone in three-point bending and impact tests and collagen fiber orientation was studied, further the proportion between absorbed energy in both tests. Maximum limits, proportional limits, stiffness and resiliency were measured in 20 left rabbit femurs by three point bending tests and energy absorbed was measured in 20 right rabbit femurs by impact tests. Collagen fiber orientation was estimated using polarized light. Regression analysis showed that in bending, stiffness has significant positive correlation $(\mathrm{R}=0,43)$ and resiliency has significant negative correlation $(\mathrm{R}=-0,46)$ with collagen fiber orientation. Energy absorbed in impact showed no significant correlation with collagen fiber orientation. The energy absorbed in impact tests was $523 \%$ greater than energy absorbed in three point bending tests.

Keywords: biomecanic; bone; bending; impact;colagen. 


\section{INTRODUÇÃO}

\subsection{O OSSO}

O osso é um tecido conjuntivo com células e fibras imersas numa substância dura e inflexível, bem adequada para as funções de sustentação e proteção que realiza. O osso fornece sustentação interna para todo o corpo e inserção para os músculos e tendões, necessária para a movimentação. Protege o cérebro e os órgãos da cavidade torácica, bem como aloja a medula óssea. $\mathrm{O}$ osso também funciona metabolicamente ao suprir uma fonte de cálcio para manter os níveis adequados no sangue (DELLMAN e BROWN, 1982).

O tecido ósseo é um tipo especializado de tecido conjuntivo formado por células e material extracelular calcificado, a matriz óssea. As células são: (1) os osteócitos, que se situam em cavidades ou lacunas no interior da matriz; (2) os osteoblastos, produtores da parte orgânica da matriz; e (3) osteoclastos, células gigantes, móveis e multinucleadas, que reabsorvem o tecido ósseo, participando dos processos de remodelação do osso (JUNQUEIRA e CARNEIRO, 1999).

\subsubsection{Estrutura macroscópica}

No corte longitudinal de um osso típico, duas formas de osso são visíveis a olho desarmado. Próximo da superfície externa, ele forma uma massa sólida e pesada, denominada osso cortical ou compacto. No sentido da superfície interna é composto de uma trama de espículas ósseas denominadas osso trabecular ou esponjoso. Não há uma demarcação nítida entre esses tipos de ossos (FIGURA 01) (DELLMANN e BROWN, 1982). 


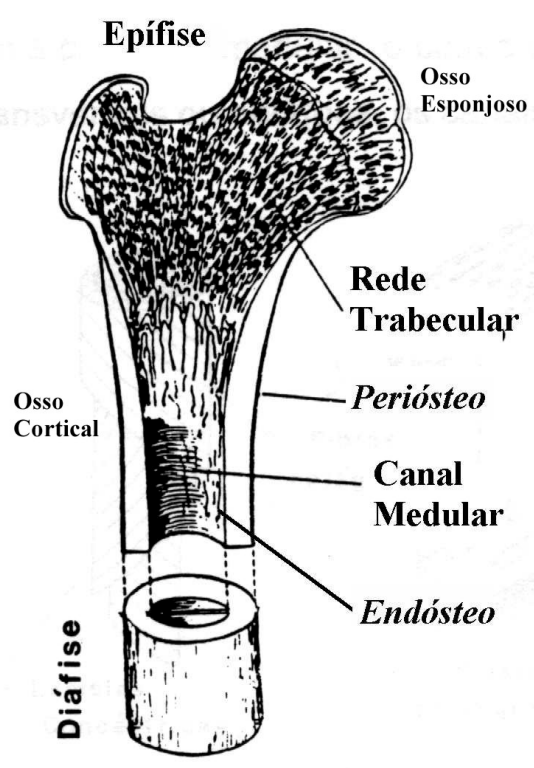

FIGURA 01 - Diferenças entre osso cortical e esponjoso.

$\mathrm{Na}$ diáfise, o osso compacto compõe a parede de um cilindro oco que circunda a cavidade medular ou medula. Nas extremidades dos ossos longos, as epífises são compostas essencialmente de osso esponjoso ou trabecular e os espaços intercomunicantes, que estão preenchidos com medula, são contínuos com a cavidade medular da diáfise (DELLMANN e BROWN, 1982).

\subsubsection{Estrutura microscópica}

Do ponto de vista microscópico o osso é classificado como:

(1) Osso primário (osso imaturo, osso não lamelar, osso reticular, osso fibroso).

(2) Osso secundário (osso maduro, osso lamelar).

\subsubsection{Osso primário}

O osso formado durante o desenvolvimento embrionário, na consolidação de fraturas ou em certos tumores ósseos é denominado osso primário. Ele possui proporcionalmente mais células e mais colágeno e menos substância cimentante e minerais do que o osso secundário, que se forma mais tarde e constitui na maior parte 
do esqueleto adulto. O osso primário é também denominado osso imaturo, osso não lamelar, osso reticular ou osso fibroso, devido à disposição e ao conteúdo de fibras colágenas. Em geral, este tipo de osso é muito rico em células, e as lacunas onde se alojam os osteócitos não são tão achatadas como as do osso maduro. A substância intercelular se caracteriza por feixes relativamente espessos de fibras colágenas, que não obedecem a qualquer disposição regular, dispondo-se de um modo irregular e, às vezes, se entrelaçando. Proporcionalmente, é menor o conteúdo de substância cimentante na substância intercelular, do que no osso maduro. Em conseqüência disto, retém menos minerais que o osso secundário (HAM, 1967).

\subsubsection{Osso secundário}

A formação e crescimento do osso secundário são caracterizados pela adição de novas lâminas às superfícies ósseas numa sequiência ordenada. Por isso, o osso secundário é também chamado lamelar ou maduro. Em sua formação e crescimento, as novas camadas são adicionadas às superfícies ósseas de modo regular FIGURA 02) (HAM, 1967).

$\mathrm{Na}$ diáfise dos ossos, as lamelas ósseas se organizam em arranjo típico, constituindo o sistema de Havers, os circunferenciais interno e externo e os intermediários FIGURA 02. Esses quatro sistemas são facilmente identificáveis nos cortes transversais da diáfise. O tecido ósseo secundário que contém sistemas de Havers, é freqüentemente chamado de tecido ósseo haversiano, sendo característico da diáfise de ossos longos, embora sistema de Havers pequenos sejam encontrados, esporadicamente no osso compacto de outros locais (JUNQUEIRA e CARNEIRO, 1999).

Cada sistema de Havers ou ósteon é constituído por um cilindro longo, às vezes, bifurcado, paralelo à diáfise e formado por 4 a 20 lamelas ósseas concêntricas. No centro desse cilindro existe um canal revestido de endósteo, o canal de Havers, que contém vasos e nervos. Os canais de Havers comunicam-se entre si, com a cavidade medular e com a superfície externa do osso, por meio de canais transversais ou oblíquos, os canais de Volkmann FIGURA 02. Estes se distinguem dos de Havers por não apresentarem lamelas ósseas concêntricas. Os canais de Volkmann atravessam as lamelas ósseas. Todos os canais vasculares do tecido ósseo aparecem 
quando a matriz óssea se forma ao redor dos vasos preexistentes (JUNQUEIRA e CARNEIRO, 1999).

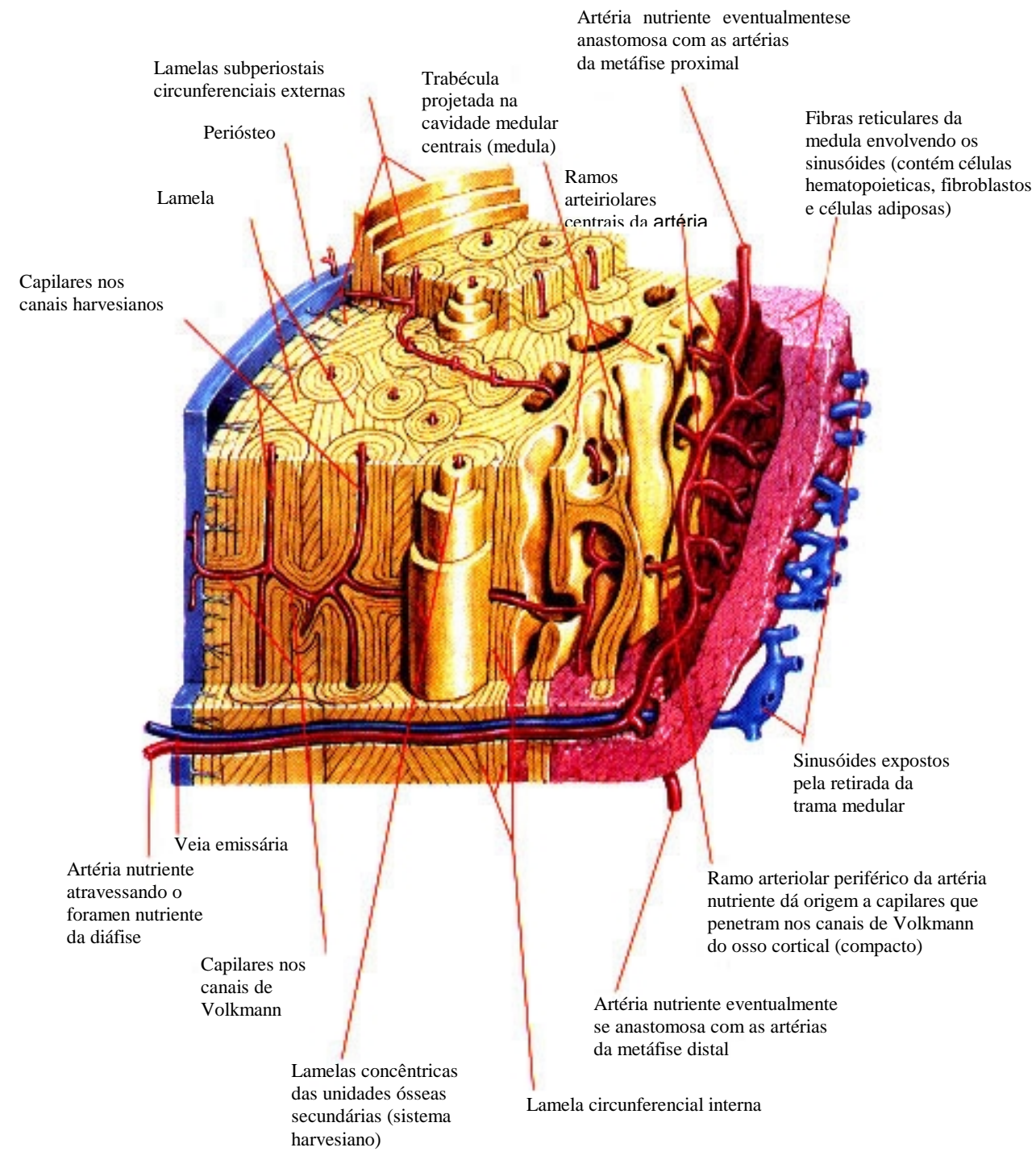

FIGURA 02 - Estrutura da diáfise do osso cortical. (Fonte: Catálogo da Novartis)

No osso esponjoso, a disposição de lamelas é um pouco menos complexa, porque as trabéculas são mais finas e podem, portanto, ser nutridas por vasos vizinhos no interior dos espaços medulares. O osso esponjoso em seus espaços intersticiais contém vasos sangüíneos, fibras nervosas, tecido adiposo e tecido hematopoiético. Embora na infância, o tecido hematopoiético seja encontrado no 
osso esponjoso de todo esqueleto, no adulto é limitado ao osso esponjoso da coluna e das cinturas pélvica e escapular (SALTER, 1995).

Os sistemas circuferenciais externos, como seus nomes indicam, são constituídos por lamelas ósseas paralelas entre si, formando duas faixas: uma situada na parte interna do osso, em volta do canal medular, a outra na parte mais externa, próxima ao periósteo (FIGURA 02. O sistema circuferencial externo é mais desenvolvido do que o interno. Entre os dois sistemas circunferenciais encontram-se os inúmeros sistemas de Havers e grupos irregulares de lamelas, geralmente de forma triangular. São os sistemas intermediários, que provêm principalmente de sistemas de Havers que foram parcialmente destruídos durante o crescimento do osso.

O osso secundário é menos celular e contém mais substância cimentante bem como mais mineral que o osso primário (SALTER, 1995).

\subsubsection{Revestimento de tecido ósseo}

As superfícies internas e externas são recobertas por células osteogênicas e tecido conjuntivo, que constituem o endósteo e o periósteo, respectivamente.

A camada mais superficial do periósteo contém principalmente fibras colágenas e fibroblastos. As fibras de Sharpey são feixes de fibras colágenas do perióstio que penetram no tecido ósseo e prendem firmemente o periósteo ao osso (FIGURA 02).

As principais funções do endósteo e do periósteo são nutrição do tecido ósseo e o fornecimento de novos osteoblastos, para o crescimento e a recuperação do osso.

\subsubsection{Composição óssea}

A parte inorgânica representa cerca de $50 \%$ do peso da matriz óssea. Os íons mais encontrados são o fosfato e o cálcio. Há também bicarbonato, magnésio, potássio, sódio e citrato em pequenas quantidades. O cálcio e o fósforo formam cristais que estudos da difração de raios $X$ mostraram ter a estrutura da hidroxiapatita, com a seguinte composição: $\mathrm{Ca}_{10}\left(\mathrm{PO}_{4}\right)_{6}(\mathrm{OH})_{2}$. Os íons da hidroxiapatita são hidratados, existindo portanto, uma camada de água e íons em volta do cristal e o líquido intersticial (JUNQUEIRA e CARNEIRO, 1999). 
A parte orgânica da matriz é formada por fibras colágenas (95\%) constituídas de colágeno do tipo I e por pequena quantidade de proteoglicanas e glicoproteínas adesivas.

A associação da hidroxiapatita com fibras colágenas é responsável pela dureza e resistência do tecido ósseo. Após a remoção do cálcio, os ossos mantêm a sua forma intacta, porém tornam-se tão flexíveis quanto os tendões. A destruição da parte orgânica, que é principalmente colágeno, pode ser realizada por incineração, e também deixa o osso com sua forma intacta, porém tão quebradiço que dificilmente pode ser manipulado sem se partir (JUNQUEIRA e CARNEIRO, 1999).

\subsection{PROPRIEDADES MECÂNICAS DO OSSO}

O comportamento mecânico do osso pode ser estudado em dois níveis: primeiro, pela realização de ensaios mecânicos em amostras uniformes do tecido ósseo, que podem ser corpos de prova retirados do osso com dimensões e geometria definidas com o ensaio a ser realizado. Segundo, pelo exame do comportamento mecânico do osso como uma unidade anatômica inteira (osso inteiro), determinando as contribuições das suas propriedades estruturais.

Os componentes fibrosos do osso consistem em três tipos - colágeno ou fibras de curso largo que se apresentam em feixes; pequenas fibras de elastina, e pequenas ramificações das fibras reticulares localizadas principalmente na medula óssea. Fibras colágenas resistem às forças de tração, visto que fibras elásticas, como o nome implica, são elásticas ou resilientes. Elas podem ser estiradas que ainda recuperam facilmente a sua forma original quando a força de tração é retirada. Fibras reticulares somente adicionam volume ao órgão (GOULD, 1993).

As cargas localizadas num osso podem ser analisadas como tendo um efeito similar às cargas localizadas em uma viga simples. $\mathrm{O}$ osso apresenta um limite de deformação elástica e um ponto crítico que delimita o alcance da deformação de uma variação elástica ou não-elástica. $\mathrm{O}$ osso não é linear nem inteiramente elástico na porção inicial da curva tensão x deformação, mas deforma-se lentamente. Portanto o osso está sujeito a uma deformação não recuperável, mas pode ceder sob tensão e se recuperar da deformação dentro do seu limite (porção elástica da curva tensão deformação). Não obstante, o osso não exibe uma alta recuperação de deformação 
quando ocorre uma significativa perda de energia ou uma histerese que ocorre durante uma carga e descarga (ANDREW, 1980 apud GOULD, 1993) ${ }^{2}$. O osso não é dútil nem frágil, e sim uma combinação de ambos, sendo a parte mineral mais frágil e a parte orgânica mais flexível.

Um osso se fortalece em tração se as fibrilas colágenas (uma fibra é composta de muitas fibrilas) estão alinhadas paralelamente com a carga de tração (REILLY e BURSTEIN, 1974). Com a utilização de um microscópio eletrônico para obseravção é possível identificar a orientação espacial da fibrila colágena no osso. Os anéis concêntricos do osso cortical contêm fibrilas colágenas que estão dispostas paralelamente a cada lamela. De qualquer modo, as fibrilas colágenas em camadas consecutivas não cursam a mesma direção. Vários pesquisadores têm descrito as direções das fibrilas nas consecutivas camadas como se alternando numa configuração longitudinal e circunferencial (em relação ao canal haversiano), ou em configuração longitudinal, circunferencial e então oblíqua das fibrilas colágenas periostiais orientadas em direção do eixo ósseo e fibrilas adicionais interconectando com a lamela concêntrica. Também foram observados ósteons com uma direção predominantemente longitudinal ou oblíqua das fibrilas colágenas ou, ainda, uma combinação de ambos (ASCENZI e BONUCCI, 1967).

O osso é uma matéria viva e embora metabolicamente dispendioso de produzir pode ser modelado e remodelado. O formato do osso é produzido pela tensão e deformação causadas pelas descargas de peso e cargas tendinosas, musculares e ligamentosas. As descargas de peso nos ossos assemelham-se a vigas levemente curvadas para que as tensões de flexão possam ser minimizadas (CURREY, 1968). A geometria das metáfises permite a transferência de grandes cargas aplicadas nas superfícies articulares dos ossos compactos das diáfises. Os locais de inserção de tendões e ligamentos no osso provêm um meio de transferir cargas da articulação para a diáfise cortical (SINGH, 1978).

O propósito do modelamento ósseo é modificar a forma e ajustar a massa de um osso para que possa resistir às tensões nas atividades diárias. A resistência óssea

${ }^{2}$ ANDREW, E. H. (1980). Fracture. In VINCENT, J. F. V.; CURREY, J. D., editors. Mechanical Properties of Biological Materials. Simposia of the Society for Experimental Biology, Number XXXIV. Cambridge, Cambridge University Press. 
pode ser alterada pelas modificações do material e propriedades geométricas do osso. Propriedades materiais incluem a porcentagem da porção orgânica e inorgânica do osso, o número de ligações cruzadas ao longo das fibrilas colágenas e a orientação destas em relação à orientação das cargas aplicadas (EVANS e VINCENTELLI, 1969). Propriedades geométricas constituem a resistência estrutural do osso, como a quantidade da área cortical e subperiosteal, o plano do momento de inércia máximo (a superfície com maior resistência à flexão). Em alguns casos, as mudanças nas propriedades materiais que enfraqueceriam o osso podem ser compensadas por modificações nas propriedades geométricas (GOULD, 1993).

A lei de Wolff (1884) relaciona o crescimento ósseo às tensões e deformações localizadas no osso; isto é, a capacidade do osso adaptar-se às mudanças de tamanho, forma e estrutura, depende das tensões mecânicas no osso. Se a tensão diminui, ocorre a reabsorção do osso periosteal e subperiosteal com a subsequente diminuição em resistência e rigidez. Se o osso está sujeito a altas tensões mecânicas, concernentes a um índice fisiológico normal, pode ocorrer hipertrofia do osso periosteal e subperiosteal, com um aumento na densidade óssea. De modo geral, os ossos longos aumentam em comprimento devido à tensão de compressão e desenvolvem protuberâncias em virtude da tensão de tração.

Uma outra propriedade importante que o osso exibe é conhecida como viscoelasticidade. Um material viscoelástico é aquele no qual as propriedades mecânicas diferem de acordo com a taxa de carregamento. Este fenômeno é devido ao fato do material escoar internamente de acordo com a carga aplicada. Um aumento na taxa de carregamento (ou deformação) aumenta o módulo de elasticidade e a resistência máxima do osso cortical enquanto há um decréscimo da deformação máxima FIGURA 03. Com pequenas taxas de deformação o osso não exibe deformação elástica apreciável mas flui como um líquido viscoso, sendo que com altas taxas de deformação o mesmo osso pode comportar-se como um sólido frágil elástico (EINHORN, 1996). 


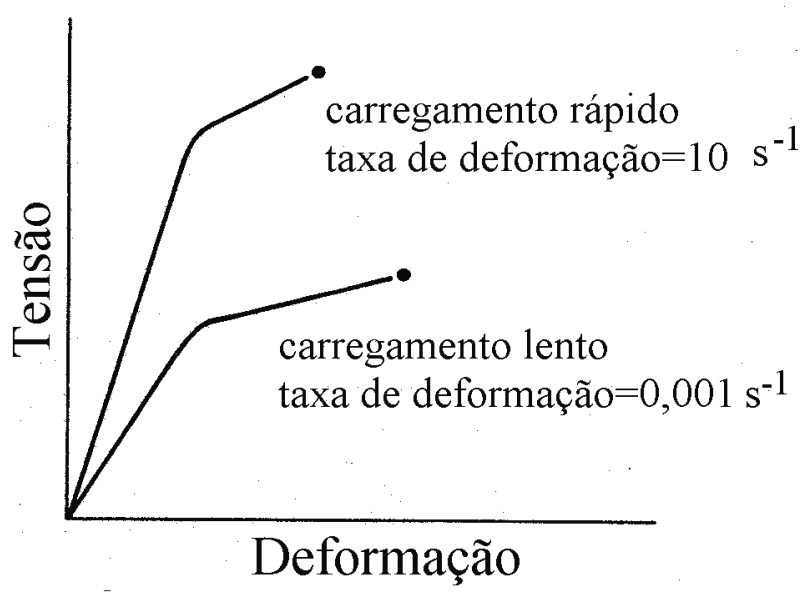

FIGURA 03 - Diferentes configurações de curvas tensão x deformação dependentes da velocidade de carregamento (Fonte: EINHORN, 1996).

\subsection{OBJETIVO}

Este estudo tem como objetivo comparar as tenacidades obtidas nos ensaios de flexão em três pontos e de impacto e verificar o índice de correlação entre a orientação das fibras de colágenos e as propriedades mecânicas obtidas nos ensaios de flexão e de impacto.

\subsection{ENSAIOS MECÂNICOS}

A determinação das propriedades mecânicas de um material é realizada por meio de vários ensaios. Esses ensaios podem ser destrutivos, quando promovem a ruptura ou inutilização do material ou não destrutivos em caso contrário. Na primeira categoria estão classificados os ensaios de tração, impacto, flexão, torção, compressão, fadiga e outros. Dentre os ensaios não destrutivos, estão os ensaios com raios X, ultra-som (SOUZA, 1977).

Os ensaios mecânicos também podem ser classificados de acordo com a velocidade de aplicação da carga em estáticos, com baixa velocidade de aplicação da carga, e dinâmicas, onde as cargas são aplicadas com altas velocidades. Dentre os ensaios estáticos estão os ensaios de tração, compressão, torção, cisalhamento e flexão e dentre os ensaios dinâmicos estão os ensaios de fadiga e impacto. 
Sob condições laboratoriais controladas, o ensaio de materiais envolve a aplicação de forças conhecidas e medida da deformação produzida. As forças podem ser divididas basicamente em três tipos de acordo com o sentido de aplicação: tração, compressão e cisalhamento FIGURA 04. A tração é produzida no material quando duas forças são aplicadas em sentidos opostos na mesma linha de aplicação com o objetivo de alongar o material, a resistência à tração provém das forças moleculares atrativas que tendem a dificultar a separação do material. A compressão é o resultado de duas forças atuando na mesma linha indo uma em direção a outra com o objetivo de achatar o material; a resistência à compressão provém das forças moleculares repulsivas, que mantém as mínimas distâncias interatômicas. Cisalhamento ocorre quando duas forças atuam paralelas uma a outra mas não na mesma linha (EINHORN, 1996).

\section{TRAÇÃO COMPRESSÃo CISALHAMENTO}
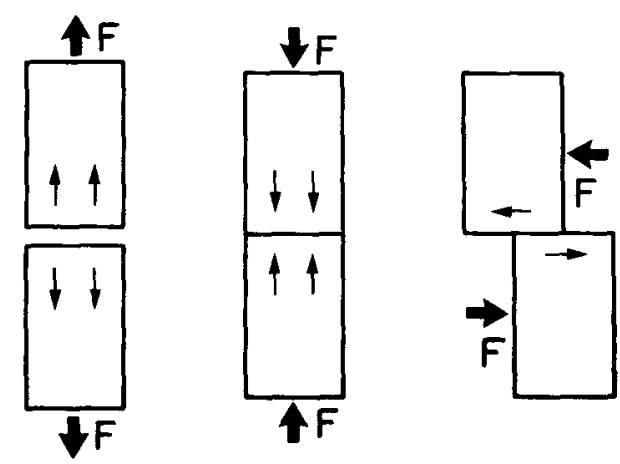

FIGURA 04 - Os três tipos básicos de tensão: tração, compressão e cisalhamento (Fonte: EINHORN, 1996)

Com a gravação das forças e deformações ocorridas durante o ensaio mecânico e conhecimento da geometria do material pode-se construir a curva tensão x deformação. A partir da curva pode ser obtida as principais propriedades dos materiais. Em baixos níveis de tensão, há um relacionamento linear entre tensão e a deformação resultante. Esta proporcionalidade é chamada módulo de elasticidade ou módulo de Young, que é a medida da inclinação da curva na porção linear que é calculada dividindo-se a tensão pela deformação em qualquer ponto desta porção. Se esta curva for gerada por ensaio de ossos inteiros, e não for possível a obtenção das propriedades geométricas, esta inclinação fornecerá a rigidez do osso. 
A porção linear da curva tensão $x$ deformação é conhecida como região elástica. No ponto onde a curva torna-se não-linear, a região elástica cede lugar a região plástica e a tensão neste ponto é conhecida como limite elástico. O ponto na curva onde isto ocorre é conhecido como ponto de escoamento. Carregamento adicional além do ponto de escoamento causará deformação permanente no material. Esta propriedade é conhecida como plasticidade e indica a resistência de um material à deformação permanente. $\mathrm{Na}$ região elástica, o material deformará somente enquanto a carga está sendo aplicada a ele, retornando ao seu tamanho e dimensões originais quando a carga é removida. Abaixo do limite elástico, a força aplicada ao material alonga suas ligações atômicas mas não rearranja suas ligações atômicas (EINHORN, 1996).

A resistência de um osso ou amostra de tecido ósseo é determinada pelo cálculo da tensão máxima aplicada no material até a ruptura. A deformação até o ponto de ruptura é conhecida como dutilidade. A integração da curva fornece a área e esta é a medida da energia de deformação. A energia total de deformação absorvida pelo material até o ponto de ruptura é chamada tenacidade. A energia injetada no material até o ponto de escoamento pode ser recuperada após a remoção da carga. A energia recuperada é conhecida como resiliência e é a medida da habilidade de armazenar energia. Embora esta energia não seja recuperável na forma útil, ela não será perdida contanto que o material não atinja a deformação permanente.

\subsubsection{Ensaio de Flexão}

Se forças atuam sobre um material de modo que elas tendem a induzir tensões de compressão em um lado da secção transversal e tensões de tração na parte restante, diz-se que o material está sob flexão. A configuração do ensaio de flexão é mostrada na FIGURA 05, com a carga localizada no centro do corpo de prova biapoiado. A cada incremento de carga aplicada no material, é anotada a deflexão correspondente, para posteriormente construir o gráfico carga x deflexão FIGURA 06). A partir deste gráfico, pode se obter as mesmas propriedades do ensaio de tração: e rigidez, limite de proporcionalidade, limite máximo, resiliência e tenacidade. 


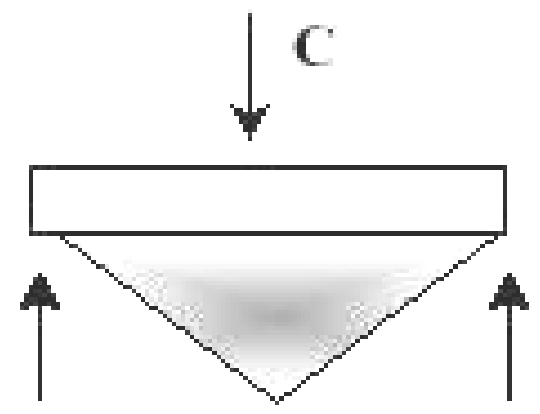

FIGURA 05 - Configuração do ensaio de flexão.

\subsubsection{Rigidez}

A rigidez é obtida pelo cálculo da inclinação da curva carga $\mathrm{x}$ deflexão na região linear e é dada pela equação:

$$
R=\operatorname{tg} \theta=\frac{\Delta C}{\Delta d}
$$

\subsubsection{Limite de proporcionalidade}

O limite de proporcionalidade é o ponto de término da relação linear entre a carga e a deflexão no gráfico carga x deflexão FIGURA 06. Após o limite de proporcionalidade termina a relação linear entre carga e deformação, sendo que após o material sofrer um pequeno escoamento, tem início a região conhecida como plástica.

\subsubsection{Limite máximo}

O limite máximo é utilizado como critério de avaliação da resistência, e é o maior valor da carga com a deformação correspondente observada em cada ensaio (ponto máximo) FIGURA 06.

\subsubsection{Resiliência}

Resiliência é a capacidade do material absorver energia quando deformado elasticamente e readquirir a forma inicial quando descarregado da carga que provocou a deformação. A resiliência é obtida calculando-se a área abaixo da curva carga x deflexão na região elástica, delimitada pelo triângulo OAB da FIGURA 06. 


\subsubsection{Tenacidade}

Tenacidade é a capacidade do material absorver energia até a ruptura. A tenacidade é calculada obtendo-se a área total abaixo da curva carga x deflexão.

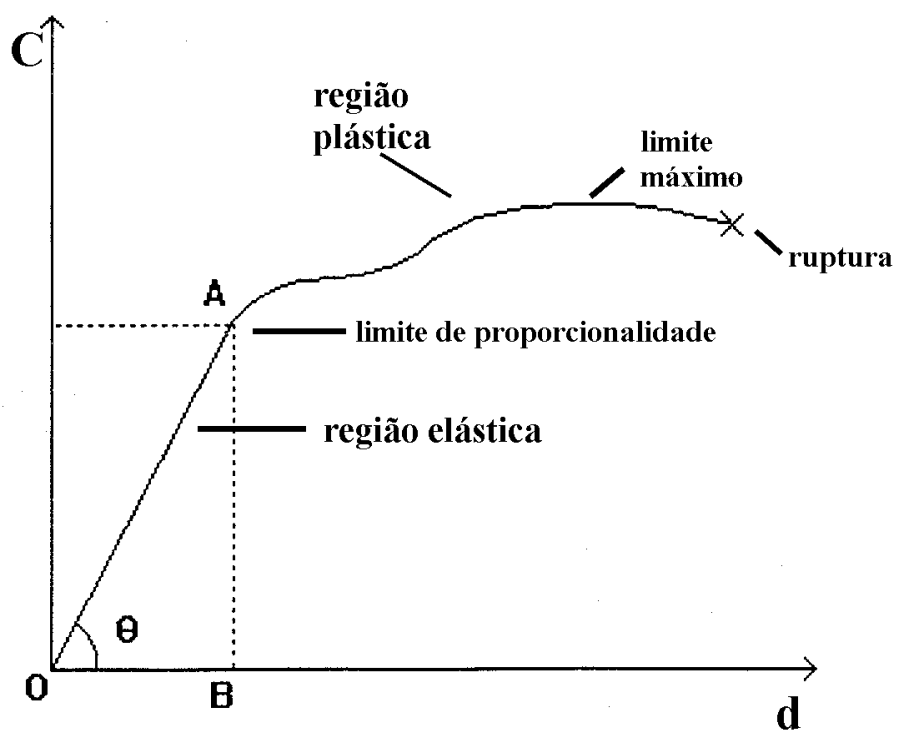

FIGURA 06 - Gráfico carga x deflexão.

O ensaio de flexão em corpos de prova que seguem o padrão da ABNT é realizado na máquina universal de ensaio, sendo que os seguintes cuidados devem ser tomados:

1. O corpo de prova deve ter um formato que permita a utilização de um vão adequado. O comprimento do corpo de prova deve ser de 6 a 12 vezes a sua largura para evitar falha por cisalhamento;

2. A área de contato com o material ensaiado deve ser tal que não haja concentração de tensões;

3. O arranjo das partes deve ser estável sob carregamento.

\subsubsection{Ensaio de Impacto}

Os materiais exibem diferentes propriedades, dependendo da taxa de aplicação da carga e da deformação resultante que irá ocorrer. A maioria dos materiais podem suportar maiores cargas antes da ruptura se o carregamento é aplicado por um longo período de tempo (ensaio estático). Se uma carga menor é 
aplicada repentinamente (ensaio dinâmico), o material pode falhar e parecer ter menos resistência. Pelo fato da resistência de muitos materiais ser dependente da velocidade de aplicação da carga, ensaios tem sido normatizados para determinar a energia requerida para quebrar o material após a aplicação de cargas repentinas. Estes ensaios são classificados como ensaio de impacto. O resultado geral de um ensaio de impacto é a energia requerida para quebrar um corpo de prova (HORATH, 1995).

Quando forças são aplicadas por curtíssimos períodos de tempo, um efeito destas forças é produzir ondas de tensão. Cargas que são aplicadas repentinamente em estruturas ou máquinas são chamadas de choque ou impacto. As cargas aplicadas repentinamente modificam as tensões e deformações produzidas e as propriedades de resistência do material (MARIN, 1962).

O impacto não envolve somente a colisão entre corpos, mas a súbita aplicação de força ou movimento a uma estrutura. Um impacto é produzido se o tempo de aplicação da carga é da mesma ordem de magnitude, ou menor que o maior período de vibração da estrutura considerada. Os danos provocados pelo impacto é naturalmente dependente das características da estrutura. Se o tempo de aplicação da carga é curto comparado com a menor freqüência natural de vibração da máquina ou estrutura, o impacto é produzido, caso contrário, se o tempo de aplicação da carga for longo, a carga é considerada estática. O tempo de aplicação de carga referido é tempo em carga aplicada vai de zero até um valor máximo (MARIN, 1962).

Para a realização do ensaio de impacto é necessária uma máquina dotada de uma massa pendular e suportes para a colocação dos corpos de prova apoiados ou engastados. O pêndulo é levantado até uma certa altura e liberado com o curso de queda direcionado ao corpo de prova. Após a colisão do pêndulo com o corpo de prova, há transferência de energia do pêndulo para o corpo de prova ocasionando sua ruptura. A quantidade de energia transferida pode ser calculado medindo-se a altura de subida do pêndulo para o calculo da energia potencial após a colisão e subtraindoa da energia potencial inicial.

Após a colisão do pêndulo não só o corpo de prova absorverá energia do pêndulo, havendo perdas de energia:

1. Pela deformação elásticas das partes do sistemas; 
2. Pela deformação plástica destas partes;

3. Pelos efeitos da histerese nas partes;

4. Pelo atrito entre os componentes da máquina;

5. Pelos efeitos da inércia nas partes móveis (HORATH, 1995).

A energia inicial do pêndulo antes do impacto é calculada da seguinte forma:

$$
E=m g h
$$

onde:

$E$ - energia potencial inicial do pêndulo (J);

$m$ - massa do pêndulo $(\mathrm{kg})$;

$h$ - altura de queda do pêndulo (m);

$g$ - aceleração da gravidade $\left(9,81 \mathrm{~m} / \mathrm{s}^{2}\right)$.

Para o cálculo da energia transferida após o impacto o pêndulo é liberado de um ângulo $\alpha$ conhecido FIGURA 07. Teoricamente se o pêndulo não encontrar resistência no percurso, então ele alcançará o ângulo $\alpha$ no lado oposto. A teoria não leva em conta os efeitos do atrito, que deve ser levado em conta para o cálculo da energia absorvida. Com a colocação do corpo de prova no caminho de colisão do pêndulo e liberação do pêndulo, após a ruptura do corpo de prova o pêndulo atingirá uma ângulo $\beta$, menor que a ângulo inicial do pêndulo (HORATH, 1995). A diferença entre os ângulos dá a energia absorvida pelo corpo de prova e é calculada a seguir:

$$
E=\operatorname{mgr}(\cos \beta-\cos \alpha)
$$

onde:

$E$ - energia absorvida pelo corpo de prova (J);

$m$ - massa do pêndulo $(\mathrm{kg})$;

$g$ - aceleração da gravidade $\left(9,81 \mathrm{~m} / \mathrm{s}^{2}\right)$;

$r$ - comprimento do pêndulo (m);

$\alpha$ - ângulo inicial (ângulo de queda);

$\beta$ - ângulo final (ângulo de subida). 


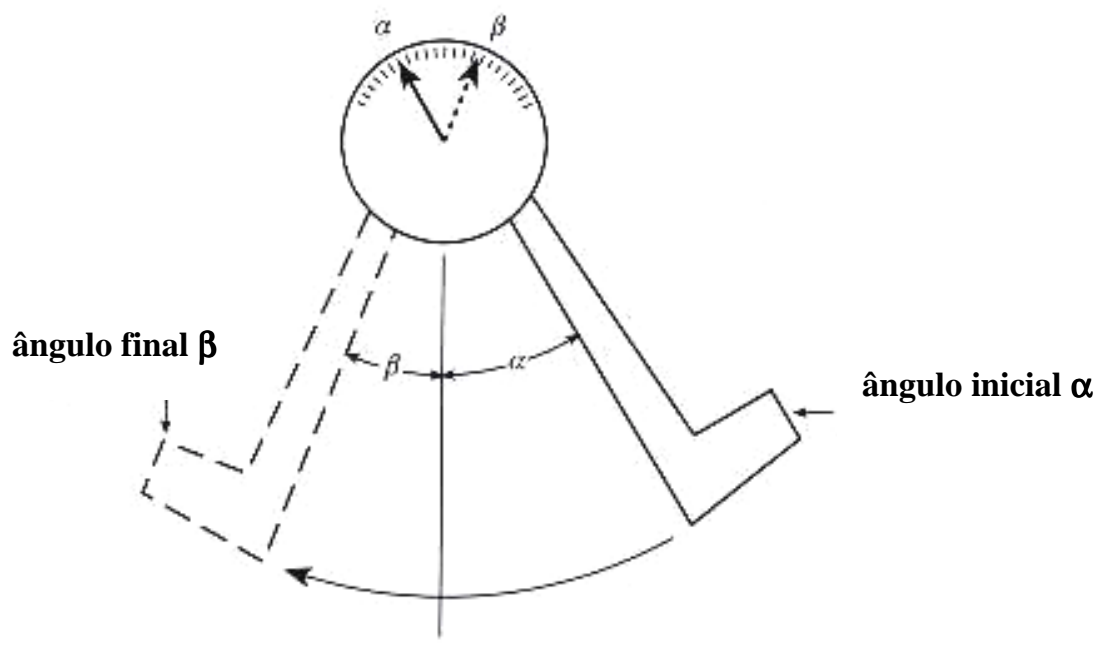

FIGURA 07 - Curso do pêndulo da máquina de impacto (Fonte: HORATH, 1995).

A energia absorvida pelo corpo de prova após a colisão com o pêndulo é chamada tenacidade. A tenacidade depende da dutilidade e resistência do material. $\mathrm{O}$ ensaio de impacto dá uma medida para comparação da tenacidade de diferentes materiais, quanto maior a energia absorvida no impacto, maior a tenacidade do material (SOUZA, 1974).

\subsection{RESISTÊNCIA MECÂNICA ÓSSEA}

A resistência de um material composto como o osso pode ser estimada pela determinação das curvas tensão x deformação na fibra e matriz dos materiais. Se as fibras e a matriz estão bem aglutinadas e se deformam juntas, a carga é dividida entre eles de acordo com a área da secção transversal de cada um. Embora muitos materiais compostos tenham uma resistência à compressão menor que à tração, o osso apresenta uma alta resistência à compressão. As fibras colágenas fornecem flexibilidade ao osso, e todos os componentes orgânicos permitem ao osso ser um bom absorvente de energia. Os componentes minerais provêm rigidez, sendo que a maior parte da carga aplicada ao osso é suportada pela fase mineral, porque o osso desmineralizado tem apenas de $5 \%$ a $10 \%$ da resistência do osso mineralizado (GOULD, 1993).

Linhas de cimento ao redor dos ósteons e dos planos entre a lamela e o sistema de Haver são geralmente áreas fracas do osso (MELICK e MILLER,1966). A rigidez óssea é inversamente proporcional ao tamanho do ósteon, à relação de 
ósteons para linhas de cimento e tamanho dos canais de Haver e Volkmann (GOTTESMAN e HASHIN, 1980).

\subsection{EFEITO DA ORIENTAÇÃO DAS FIBRAS DE COLÁGENO SOBRE AS PROPRIEDADES MECÂNICAS DOS OSSOS}

\subsubsection{Medida das fibras de colágeno após polarização}

Muitas investigações anteriores procuraram obter uma correlação entre a histologia do osso cortical e as propriedades mecânicas (CURREY, 1959; ASCENZI e BONUCCI, 1964, 1967; HERT et al., 1965; REILLY e BURSTEIN, 1974; CARTER e SPENGLER, 1978). O osso pode ser descrito por diversas variáveis composicionais e microestruturais, incluindo densidade, porosidade, quantidade de mineral ou cálcio, orientação das fibras de colágeno, anisotropia e classificação histológica.

Os ósteons secundários e seus fragmentos podem ser classificados como claro, intermediário e escuro segundo ASCENZI e BONUCCI (1964), tendo como base a orientação das fibras de colágeno, determinada pela sua aparência após polarização da superfície FIGURA 08.

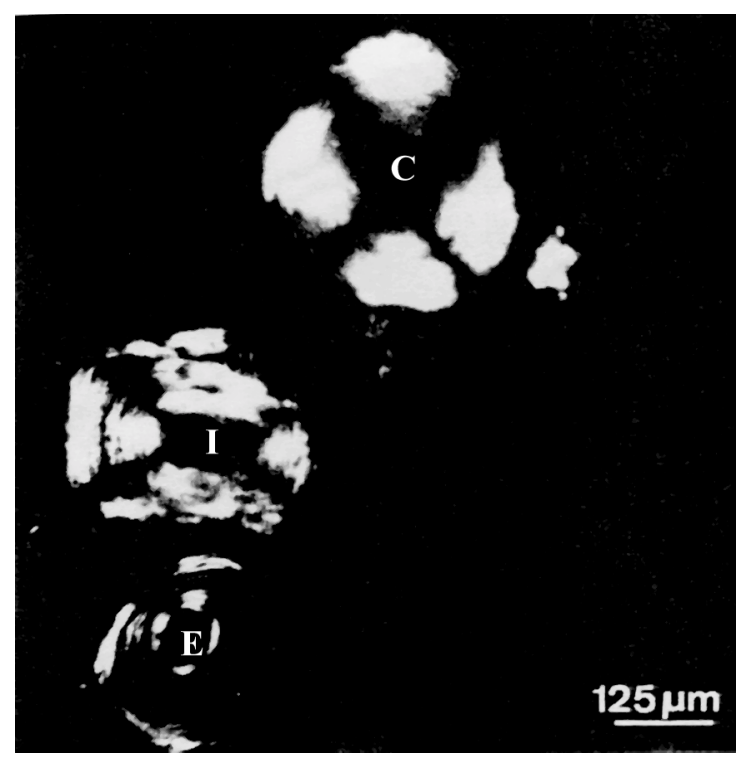

FIGURA 08 - Ósteons claro (C), escuro (E) e intermediário (I) obtidos de uma secção transversal fina de um osso tibial. x75. 
Nos ósteons claros (tipo I) predomina a existência de fibras transversas ao eixo ósseo, sendo que sob luz polarizada, na secção transversal destas amostras os ósteons aparecem claros. Os ósteons escuros (tipo III) possuem fibras longitudinais ou aproximadamente longitudinais e sob luz polarizada, na secção transversal das amostras os ósteons aparecem escuros Nos ósteons intermediários (tipo II) há a presença de ósteons longitudinal, formando um ângulo de aproximadamente $90^{\circ} \mathrm{com}$ o feixe de fibras transversais da lamela posterior produzindo um brilho intermediário entre os ósteons claro e escuro sob luz polarizada (FIGURA 09].

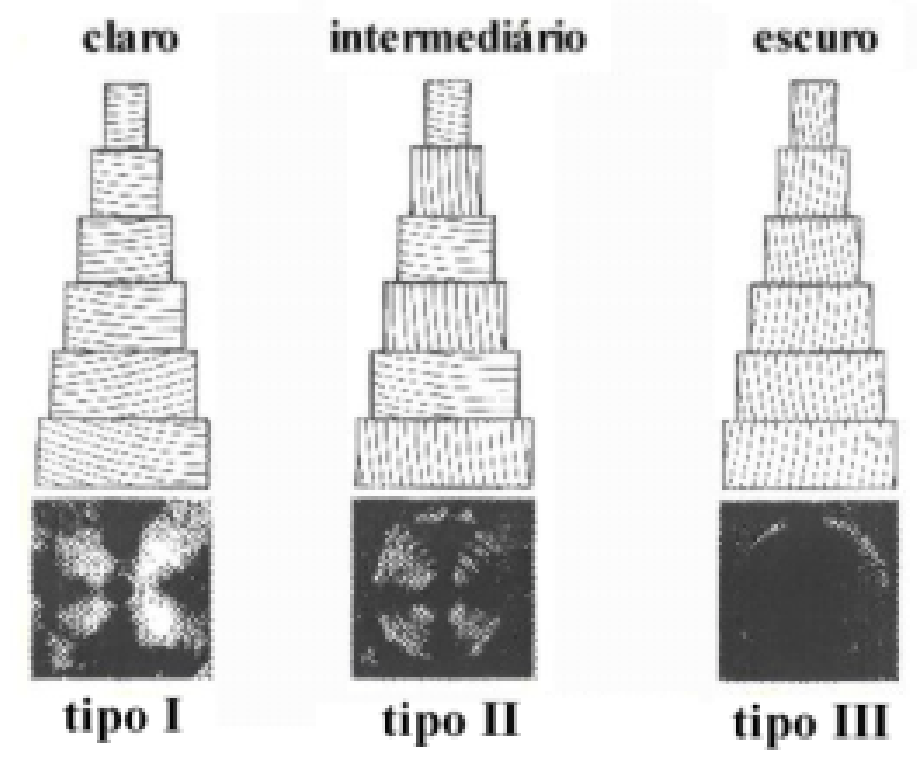

FIGURA 09 - Modelo de ASCENZI e BONUCCI (1968) dos três tipos de ósteons de secção transversal sob polarização com diagramas ilustrando a orientação do feixe de fibras em lamelas sucessivas.

As classificações da FIGURA 09 são válidas se houver rotação do polarizador de $90^{\circ}$, se a rotação for somente de $45^{\circ}$, os resultados são os seguintes:

ósteon claro permanece claro

ósteon escuro torna-se claro

ósteon intermediário não modifica sua aparência

Em uma rotação completa de $360^{\circ}$ do polarizador, os resultados são os seguintes:

ósteon claro aparece $4 \mathrm{x}$ claro e $4 \mathrm{x}$ escuro (a cada $45^{\circ}$ )

ósteon escuro aparece claro durante toda a rotação 
ósteon intermediário não muda durante a rotação.

\subsubsection{Relação entre a microestrtura e as propriedades mecânicas dos ossos}

O estudo das relações entre as propriedades mecânicas dos ossos e as propriedades microestruturais vem sendo feito desde o final dos anos 40 , porém nesta época dava-se ênfase ao estudo da quantidade de mineral existente no osso, não levando em conta o efeito dos outros componentes.

EVANS (1958) procurou dar um enfoque diferente às propriedades microestruturais, estudando as relações entre a estrutura osteônica e a resistência à tração de ossos humanos. Para isso, realizou ensaio de tração em corpos de prova de fêmures e fíbulas humanos, sendo que após os ensaios retirou e descalcificou secções ósseas próximas à fratura. Os ossos com maior resistência à tração tinham como principal característica microestrutural menor quantidade de ósteons, sendo que estes ósteons possuíam grande tamanho e maior quantidade de fibras de colágeno orientadas longitudinalmente.

Com os corpos de prova de fêmures bovinos ensaiados sob tração, CURREY (1959) procurou verificar uma correlação entre a existência de sistemas haversianos e a tensão de ruptura e uma possível relação entre o local de retirada dos corpos de prova e a tensão de ruptura. Com relação aos locais de retirada dos corpos de prova notou que apenas houve diferença significativa entre os corpos de prova retirados das partes anterior e posterior, não existindo diferença entre as outras partes. Com relação ao tipo de osso ficou evidenciado que o osso haversiano possui menor resistência quando comparado com o osso não haversiano. CURREY explica esta diferença citando duas razões principais: 1) O osso haversiano reduz a quantidade de osso presente; 2) $\mathrm{O}$ osso haversiano reduz a quantidade de cálcio do osso devido ao fato do osso haversiano não estar totalmente mineralizado.

ASCENZI e BONUCCI (1967), realizando ensaio de tração em ósteons retirados de fêmures humanos e bovinos, encontraram maior resistência à tração e módulo de elasticidade e menor deformação em ósteons com arranjo marcadamente longitudinal com relação ao eixo do ósteon, quando estes foram comparados com os ósteons cujos feixes de fibras nas lamelas sucessivas mudam com um ângulo aproximado de 90 graus. Os pesquisadores também descobriram que a resistência à 
tração do ósteon independe da idade e que o aumento da calcificação do ósteon aumenta o módulo de elasticidade e redução do teor de água do ósteon também aumenta o módulo de elasticidade.

EVANS e BANG (1967) estudaram as propriedades mecânicas e microestruturais de corpos de prova retirados de tíbias, fíbulas e fêmures provenientes de humanos e procuraram verificar a correlação entre as propriedades de cisalhamento e tração com a porcentagem de ósteons e seus fragmentos, porcentagem de espaços e lamelas intersticiais. Notaram que o aumento da porcentagem e da área ocupada por ósteons, aumenta significativamente a dureza e reduz a resistência à tração, resistência ao cisalhamento e módulo de elasticidade. Isto foi explicado pela fato de o aumento do número de ósteons, aumentar a quantidade de canais haversianos que aumentam as concentrações de tensões e a quantidade de linhas de cimento, que são pontos de fragilidade da estrutura óssea por onde se iniciam as fraturas.

ASCENZI e BONUCCI (1968) realizaram ensaios de compressão em ósteons retirados de fêmures humanos e bovinos e encontraram uma maior resistência à compressão do ósteons com feixes de fibras orientadas transversalmente, menor resistência para os ósteons que possuem os feixes de fibras orientadas longitudinalmente e resistência intermediária para os ósteons com feixes de fibras que mudam de direção em lamelas sucessivas com ângulo aproximado de 90 graus. O módulo de elasticidade foi maior nos ósteons com feixe de fibras orientadas transversalmente, sendo que este aumenta com a calcificação do ósteon. A idade não teve influência sobre as propriedades mecânicas.

Com o objetivo de estudar a relação entre as propriedades mecânicas e quantidade de fibras de colágeno e calcificação dos osso, VINCENTELLI e EVANS (1971) realizaram ensaio de tração em corpos de prova de tíbias humanas, comparando as propriedades obtidas com o tipo de ósteons obtido na secção transversal na microscopia polarizada. Verificaram que a resistência à tração e deformação tiveram alta correlação positiva com as amostras formadas principalmente por ósteons escuros e alta correlação negativa com os ósteons claros.

Em 1983, BARBOS et al. fizeram uma análise preliminar da distribuição das unidades intersticiais e osteônicas do osso compacto de acordo com a sua 
estrutura, grau de calcificação e propriedades mecânicas, levando-se em consideração os esforços de tração e compressão. Eles cortaram secções não descalcificadas de $100 \mu$ de fêmures, analisando-as na microscopia de polarização e medindo a área ocupada por lamelas claras na secção óssea. Eles notaram que onde o eixo femoral suporta cargas compressivas, na região medial e posterior, o tipo de lamela predominante é aquela cujas fibras têm curso transversal (lamelas claras). Onde o eixo femoral está sujeito a cargas de tração, as fibras têm curso longitudinal com a predominância de lamelas escuras. Esta distribuição de lamelas de acordo com sua orientação revelou algum grau de correlação com a distribuição de tensões ao longo do eixo femoral

MARTIN e ISHIDA (1989) realizaram ensaio de tração em corpos de prova de fêmures bovinos com o objetivo de verificar a correlação entre as propriedades mecânicas e as seguintes propriedades microestruturais: orientação das fibras de colágeno, densidade, mineralização e porosidade. Concluíram que a variável que mais se correlacionou significativamente com a resistência à tração foi a orientação das fibras de colágeno. Os autores sugerem que a porosidade e mineralização são propriedades menos importantes do que a orientação das fibras de colágeno na determinação das propriedades mecânicas de tração.

Como ainda não haviam realizado ensaio de flexão em ósteons, em 1990, ASCENZI et al. retiraram ósteons de fêmures humanos e realizaram ensaios de flexão em três pontos em ósteons longitudinais e alternados. Os ósteons longitudinais foram menos capazes de suportar cargas de flexão que os ósteons alternados, flexionado-se facilmente e com a ruptura ocorrendo somente na região carregada em tração. Os ósteons alternados foram mais rígidos, com a ruptura atravessando o ósteon.

MARTIN e BOARDMAN (1993) realizaram ensaio de flexão em corpos de prova de fêmures bovinos com o objetivo de verificar a correlação entre as propriedades mecânicas e as propriedades microestruturais. Realizaram análise de regressão múltipla, obtendo a correlação entre elas. As propriedades microestruturais estudadas foram: orientação das fibras de colágeno, porosidade, densidade e mineralização. Concluíram que dentre as propriedades microestruturais, a orientação das fibras de colágeno teve maior correlação com a resistência à flexão e segunda 
maior correlação com o módulo de elasticidade, sendo a orientação das fibras de colágeno um forte determinante da resistência à flexão e rigidez do osso cortical.

Mais recentemente MARTIN et al. (1996) realizaram ensaio de flexão em quatro pontos e ensaio de fadiga em corpos de prova retirados das regiões dorsal, medial e lateral da diáfise medial do metacarpo de eqüinos, depois estimaram a quantidade de fibras de colágeno orientadas longitudinalmente através da microscopia de polarização. Eles concluíram que a região com maior quantidade de fibras de colágeno foram as regiões dorsal e lateral, sugerindo que estas recebem mais cargas de tração que a região lateral que possui menos fibras longitudinais, sendo que as diferenças regionais nas propriedades mecânicas do osso metacarpo eqüino são correlacionadas com a orientação das fibras de colágeno na região. 


\section{MATERIAIS E MÉTODOS}

Os animais utilizados para realização dos ensaios foram 20 (vinte) coelhos da raça Nova Zelândia com peso entre 2 e 2,5 kg, que corresponde ao animal já na fase adulta. Os coelhos foram fornecidos pelo Biotério Central da Prefeitura do Campus da USP de Ribeirão Preto.

Os animais foram sacrificados com injeção letal de anestésico, e os fêmures foram retirados, dissecados, armazenados em solução fisiológica e conservados em freezer $\mathrm{a}-20^{\circ} \mathrm{C}$.

\subsection{ENSAIO DE FLEXÃO}

Os ensaios de flexão em três pontos foram realizados com os 20 fêmures esquerdos, utilizando-se a máquina universal de ensaio do Laboratório de Bioengenharia da FMRP-USP. Para obtenção da carga aplicada foi utilizada uma célula de carga $\operatorname{KRATOS}^{\circledR}$ modelo $\mathrm{KM}$ de $50 \mathrm{kgf}$ ligada a uma ponte de extensometria SODMEX ${ }^{\circledR}$ modelo CAE 201. As deformações foram medidas por um relógio comparador MYTUTOYO ${ }^{\circledR}$ com precisão de centésimos de milímetros.

Os fêmures foram retirados do freezer 24 horas antes do ensaio, colocados na geladeira e retirados horas antes do ensaio para que pudessem entrar em equilíbrio térmico. Os fêmures foram colocados sobre apoios com distância de $55 \mathrm{~mm}$ entre si, onde a aplicação da carga foi realizada no sentido ântero-posterior, com uma précarga de 0,5 kgf e tempo de acomodação do sistema de 1 minuto (FIGURA 10. Os ensaios foram realizados até a ruptura total do osso. A velocidade de aplicação de carga foi $0,30 \mathrm{~mm} /$ minuto, e as medidas realizadas a cada $0,02 \mathrm{~mm}$ de deflexão. 


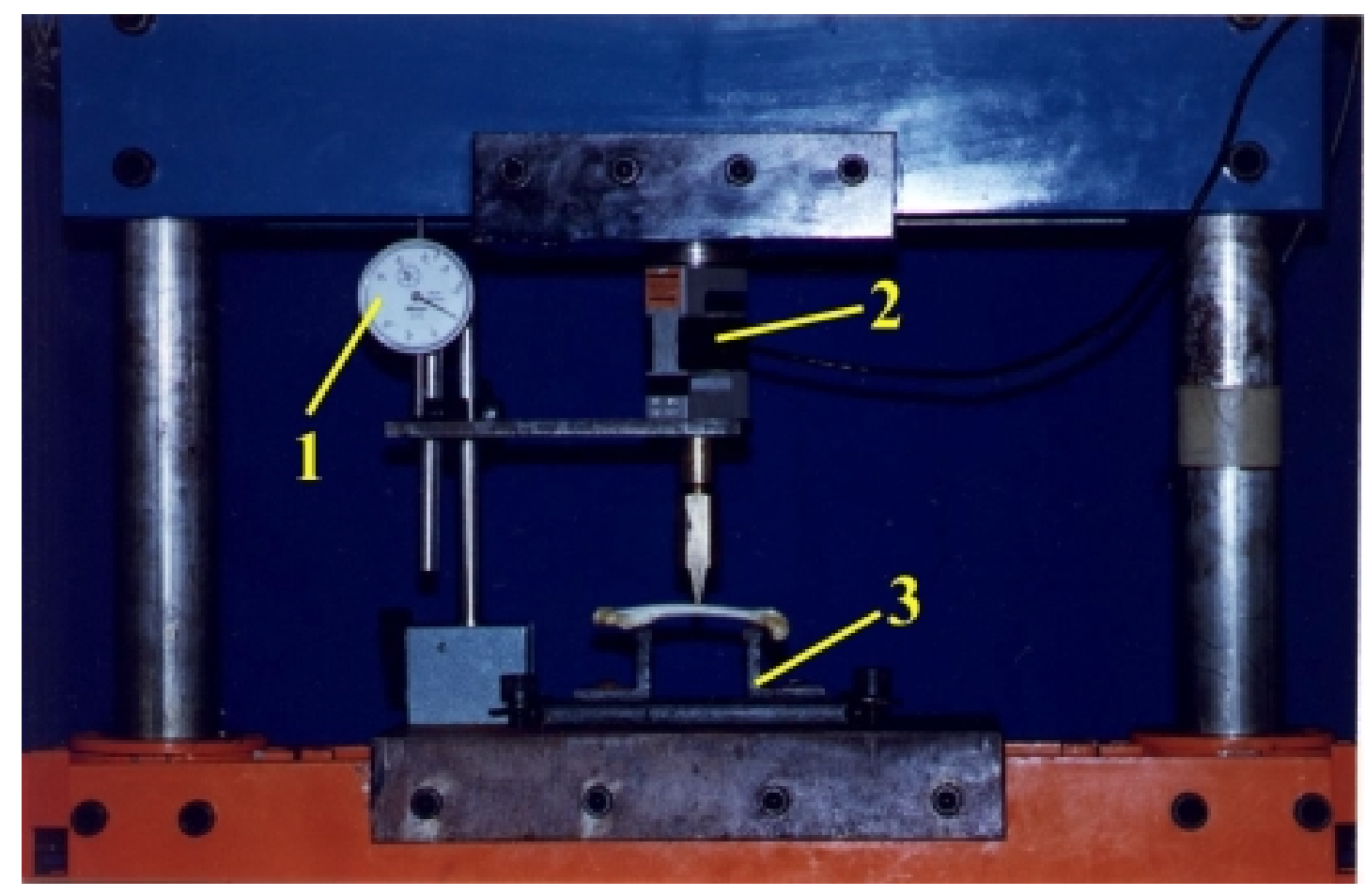

(1) Relógio Comparador

(2) Célula de Carga

(3) Apoios

FIGURA 10 - Colocação do fêmur no ensaio de flexão.

A partir dos valores de carga e deflexão obtidos no ensaio foi construída a curva carga x deflexão e calculadas as seguintes propriedades:

1. Limites de proporcionalidade

2. Limites máximos

3. Rigidez

4. Resiliência

5. Tenacidade 


\subsection{ENSAIO DE IMPACTO}

Os ensaios de impactos foram realizados na Máquina de Impacto PSd 50/15 (FIGURA 11) do Departamento de Materiais da EESC - USP.

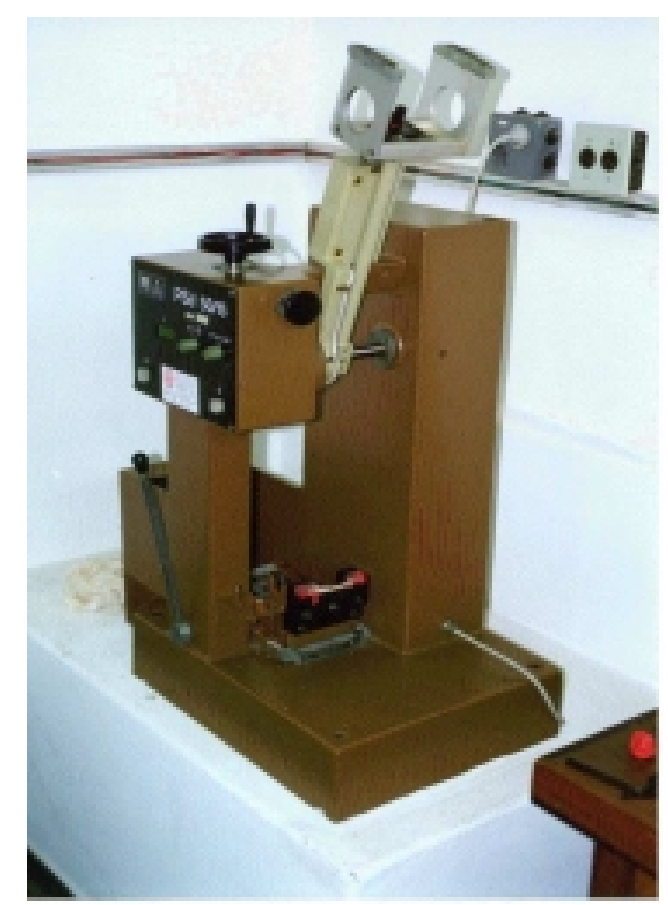

FIGURA 11 - Máquina de Impacto PSd 15/50 utilizada no ensaio de impacto.

Para os ensaios de impacto foram utilizados os 20 fêmures direitos que foram preparados utilizando a mesma técnica de descongelamento do ensaio de flexão.

Para a realização dos ensaios foi utilizado um martelo pendular tipo Charpy e um suporte para a colocação dos ossos com distância entre os apoios de $55 \mathrm{~mm}$. Esta distância manteve um padrão com o ensaio de flexão. porém para a obtenção desta distância foi necessária a confecção de dois encostos de metal, que foram colados ao suporte com cola de secagem rápida. Este procedimento foi necessário devido ao fato dos suportes para o ensaio de impacto serem padronizados, e de acordo com a norma ABNT, o suporte com vão mais próximo de $55 \mathrm{~mm}$ é o de 60 $\mathrm{mm}$. Por isso foram feitos encostos (calços) que presos às duas extremidades de apoio do suporte propiciassem uma distância entre os vãos de $55 \mathrm{~mm}$. 
Os fêmures foram colocados no suporte de maneira que o impacto ocorresse no sentido ântero-posterior FIGURA 12). Os valores de energias absorvidas no impacto dadas em Joules ( $\mathrm{J}$ ) foram obtidos através da leitura direta do mostrador digital da máquina.

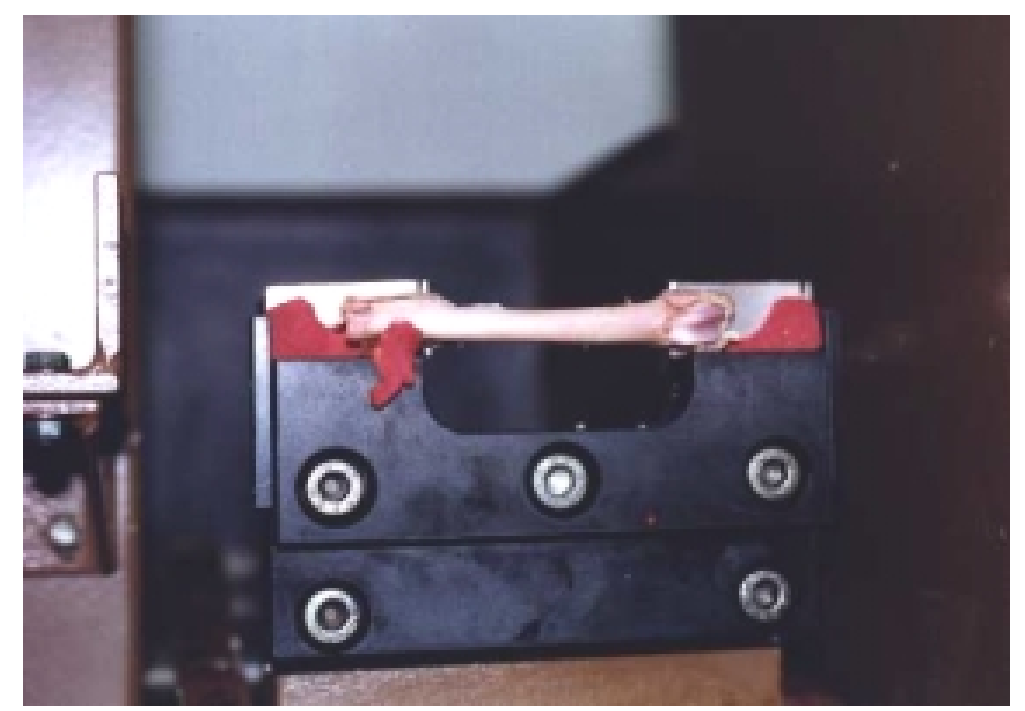

FIGURA 12 - Colocação do fêmur no suporte de ensaio.

\subsection{PREPARAÇÃO DAS LÂMINAS HISTOLÓGICAS}

Após a realização dos ensaios os ossos foram fixados em formol a $10 \%$ e após 10 dias foram colocados em álcool a 70\%. Para a preparação das lâminas histológicas, foi realizado o procedimento descrito a seguir:

1. Foram feitos cortes próximos às áreas fraturadas no sentido transversal com espessura aproximada de $1 \mathrm{~mm}$ FIGURA 13, utilizando uma serra com disco diamantado;

2. As peças histológicas foram desgastadas manualmente com o atrito em lixas d'água com densidades granulométricas crescentes (320, 400, 500, 600), que eram trocadas de acordo com a espessura da peça, sob fluxo contínuo de água, fazendo-se movimentos circulares lentos e sucessivos, alternando-se os lados da peça. Para um desgaste homogêneo, a peça foi desgastada com auxílio de uma lâmina de vidro colocada abaixo das lixas; 
3. Para as medidas das espessuras das peças foi utilizado um micrômetro, procurando desgastar a peça até uma espessura aproximada de $100 \mu \mathrm{m}$;
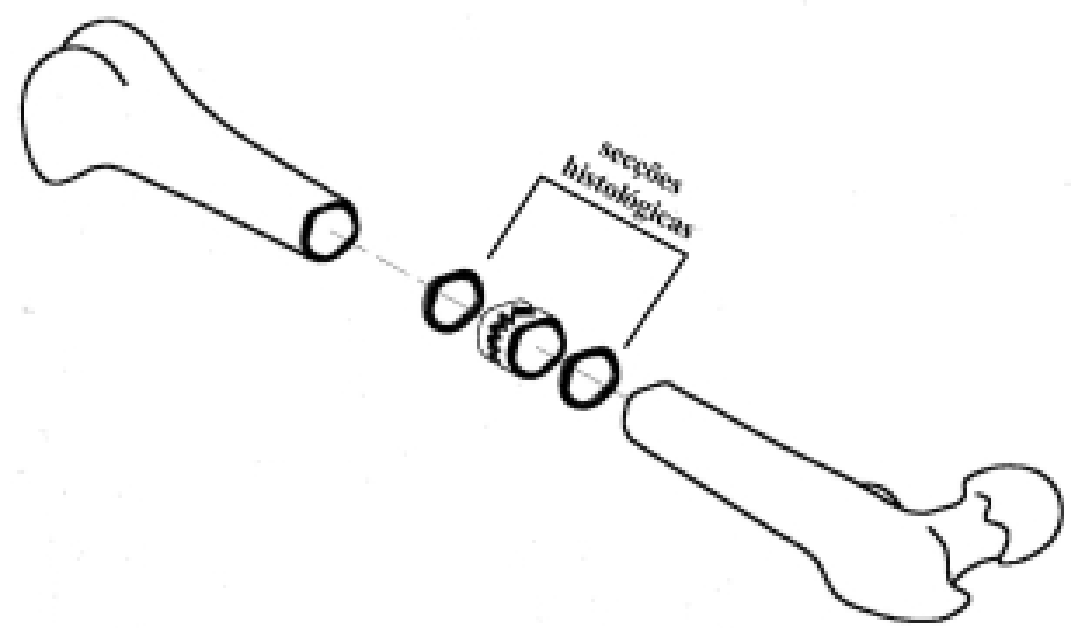

FIGURA 13 - Cortes de secções transversais nos fêmures ensaiado.

4. A peça foi colocada em lâmina, com óleo mineral não fluorescente (Nujol ), e recoberta com lamínula

5. A fixação da lamínula à lâmina foi realizada aplicando parafina líquida nas extremidades.

\subsection{CAPTURA DAS IMAGENS DAS SECÇÕES TRANSVERSAIS}

Um microscópio Zeiss Axiolab, utilizando uma objetiva de aumento de $2,5 \mathrm{x}$ e possuindo filtros analisador e polarizador colocados no caminho de transmissão da luz (um filtro sobre a objetiva e outro sobre o condensador), foi utilizado para observar a secção óssea. Os filtros foram rotacionados de modo que houvesse polarização da luz transmitida, obtendo-se um campo escuro, evidenciando as fibras de colágeno devido à sua propriedade de birrefrigência. 


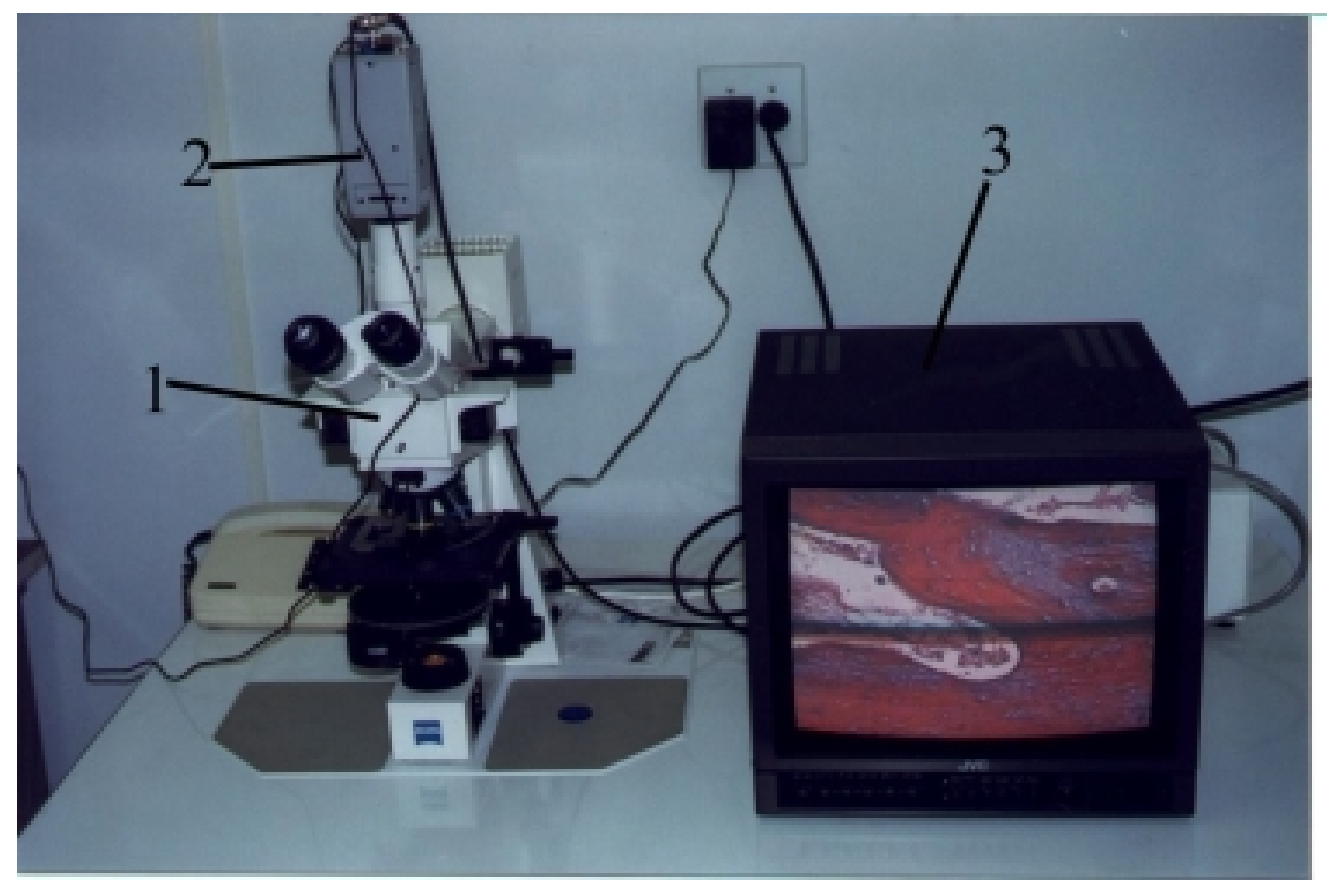

(1) Microscópio Zeiss ${ }^{\circledR}$ Axiolab

(2) Câmera Digital

(3) Monitor de Alta Resolução

FIGURA 14 - Sistema utilizado para aquisição das imagens das lâminas histológicas.

As imagens das secções foram capturadas por uma câmera digital SONY modelo SSC-DC54 FIGURA 14, acoplada ao microscópio e digitalizadas para o formato de leitura do computador (Bitmap TIFF - Tagged Image File Format) utilizando uma placa de aquisição de imagens SNAPPY 3.0. A captura das imagens de toda a secção óssea foi feita por varreduras (de 11 a 16), já que a objetiva focaliza somente uma parte da secção FIGURA 15.

\subsection{MEDIDA DAS FIBRAS DE COLÁGENO}

Com as imagens das secções sob o efeito de luz polarizada FIGURA 16, foi possível identificar as fibras de colágeno e através dos processos thresholding e binarização da imagem (RUSS, 1995) FIGURA 17, a área de interesse foi selecionada. A área ocupada pelas fibras de colágeno nas secções foi medida utilizando os softwares UTHSCSA Image Tools e Scion Image, cedidos pelo Departamento de Morfologia da Faculdade de Medicina de Ribeirão Preto (FMRP - 
USP). Fazendo o preenchimento de toda a secção óssea e repetindo os procedimentos descritos anteriormente, foi calculada a área total ocupada pela secção óssea (FIGURA 18). A área relativa $A_{R F}$ foi calculada dividindo-se a área ocupada pelas fibras de colágeno pela área total da secção:

$$
A_{\mathrm{RF}}=\frac{\text { Área ocupada pelas fibras de colágeno }}{\text { Área total da secção }}
$$

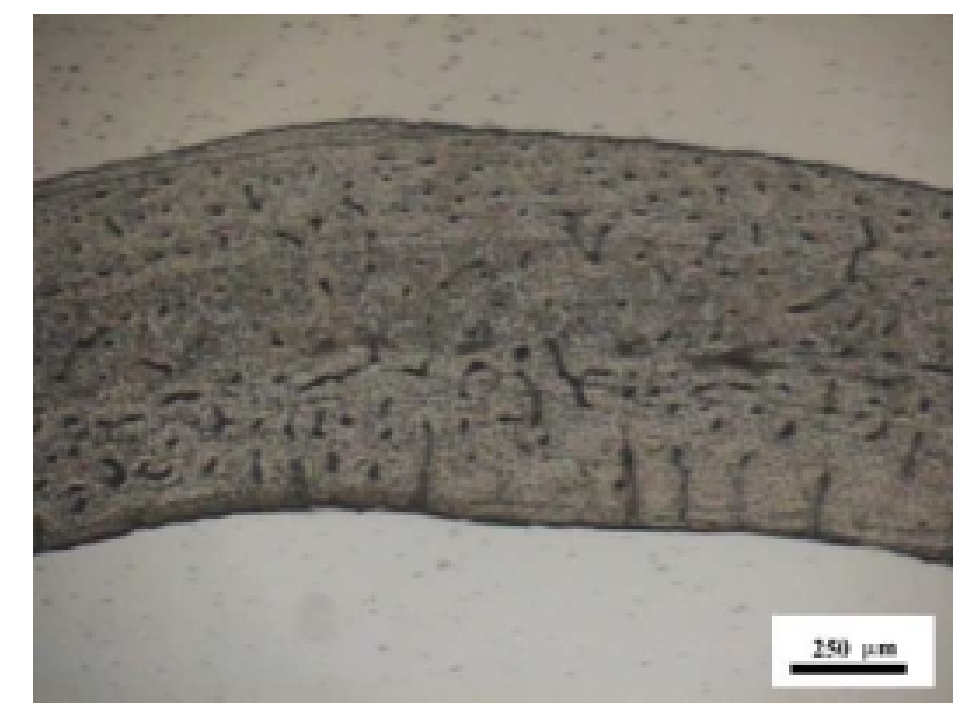

FIGURA 15 - Imagem de parte da secção transversal capturada antes da polarização.

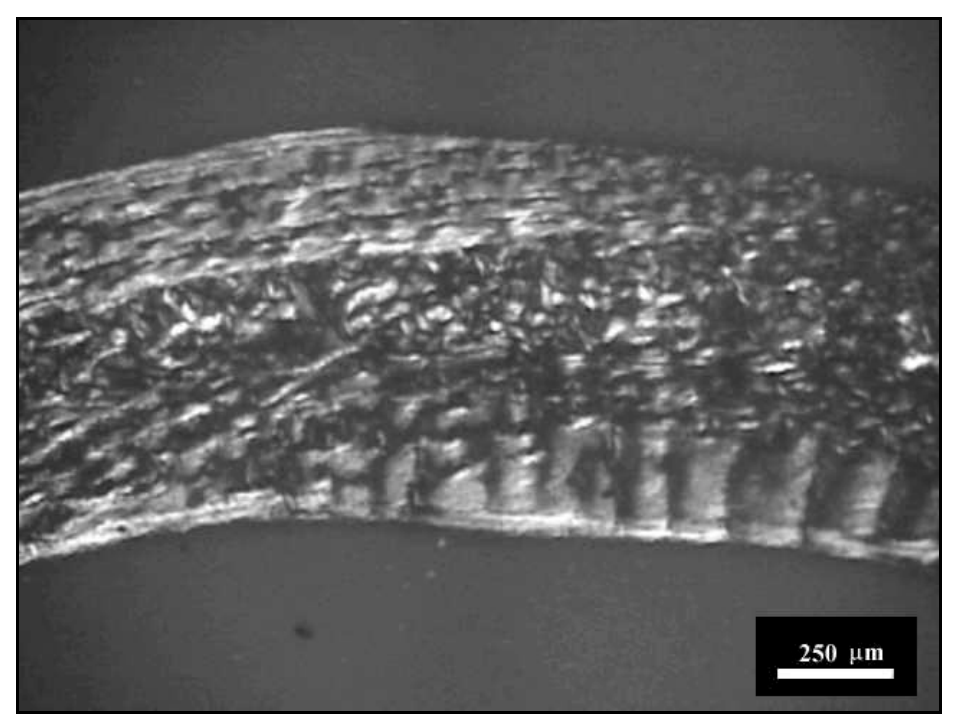

FIGURA 16 - Secção transversal após polarização da luz. 


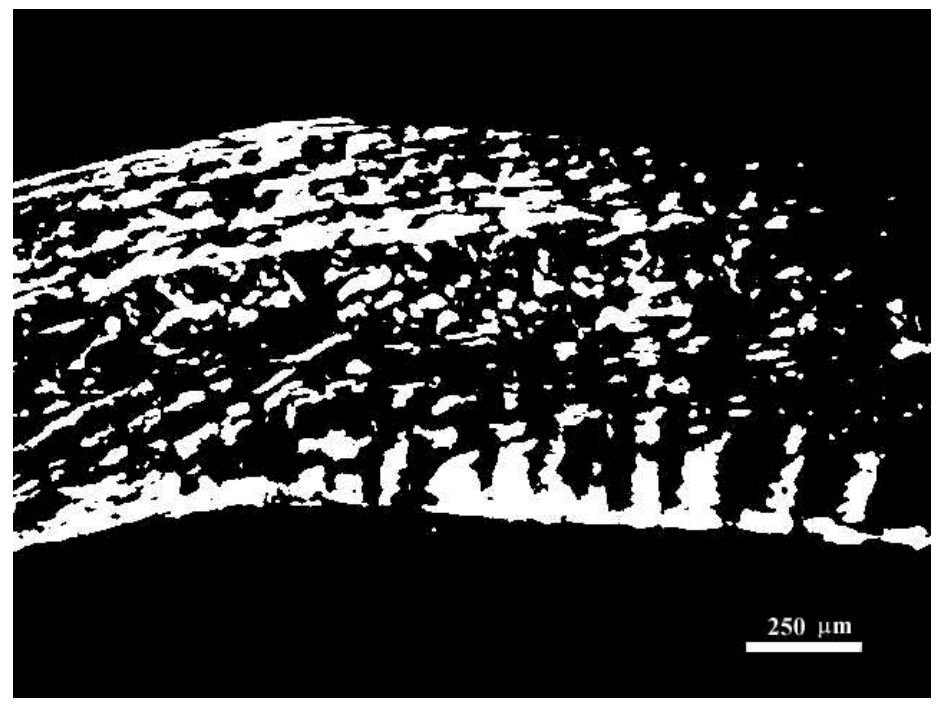

FIGURA 17 - Secção transversal após thresholding e binarização.

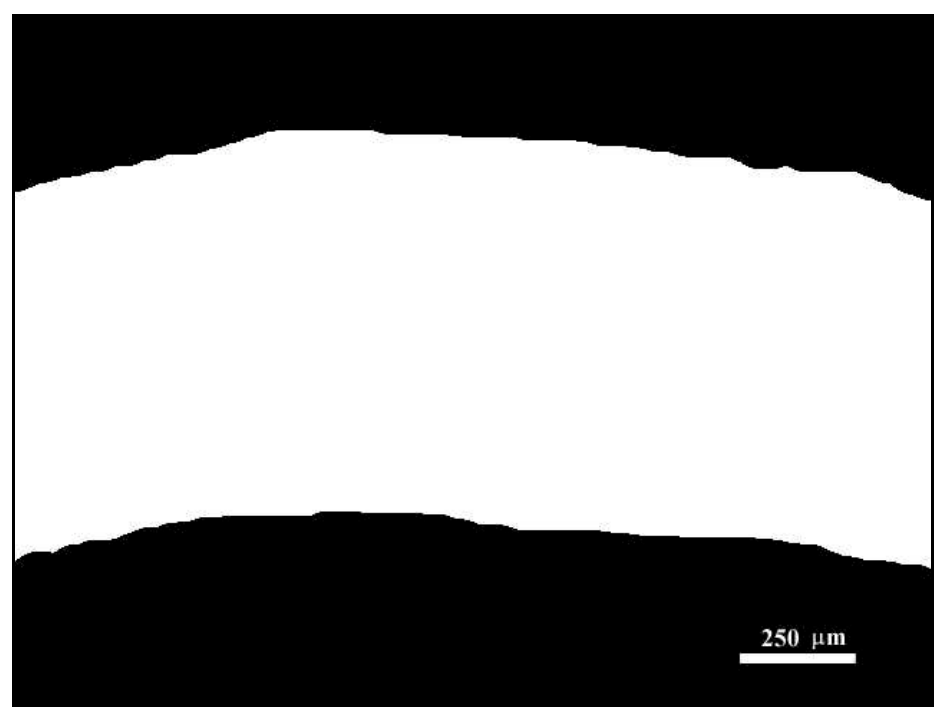

FIGURA 18 - Cálculo da área total ocupada pela secção óssea. 


\subsection{ANÁLISE ESTATÍSTICA}

As tenacidades obtidas nos ensaios de flexão e de impacto foram comparadas e testadas utilizando o teste t de Student $(\mathrm{p}<0,05)$.

Os índices de correlação linear (r) entre a área relativa ocupada pelas fibras e os valores das propriedades mecânicas do ensaio de flexão em três pontos e de impacto foram calculados e testados utilizando o teste t de Student, com nível de significância de 5 por cento.

As testes estatísticos e o cálculo dos índices de correlação foram feitos utilizando a planilha eletrônica Microsoft ${ }^{\circledR}$ Excel 95. 


\section{RESULTADOS}

O gráfico carga x deflexão para os 20 fêmures obtidos a partir do ensaio de flexão é mostrado na FIGURA 19.

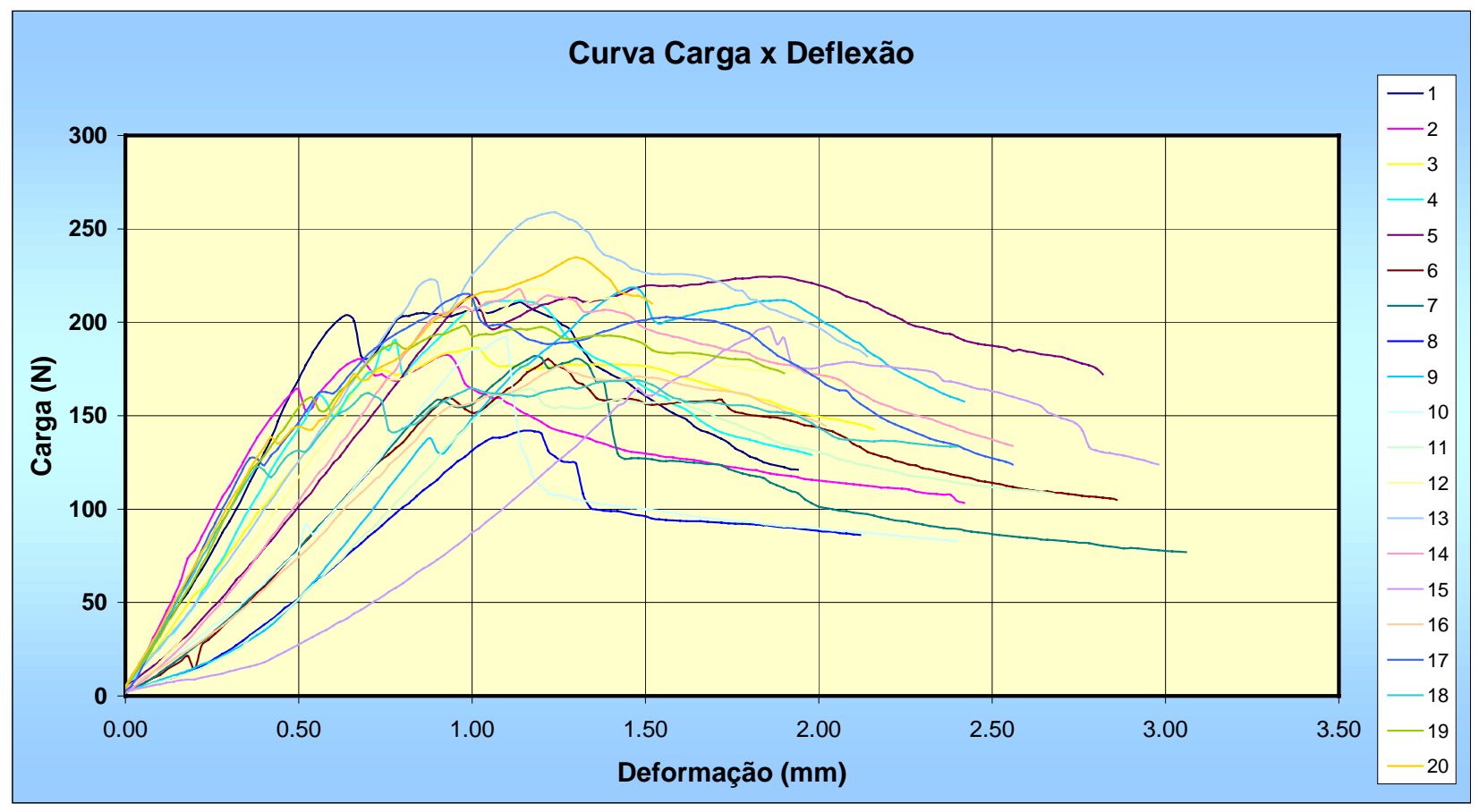

FIGURA 19 - Curva carga x deflexão para os 20 fêmures ensaiados. 
A TABELA 01 apresenta as propriedades mecânicas obtidas nos ensaios de flexão para os 20 fêmures esquerdos.

TABELA 01 - Propriedades mecânicas de flexão.

\begin{tabular}{cccccccc}
\hline & \multicolumn{2}{c}{ limite máximo } & \multicolumn{2}{c}{ limite de } \\
proporcionalidade & rigidez & resiliência & tenacidade \\
\hline $\boldsymbol{N}$ & $\boldsymbol{C}(\boldsymbol{N})$ & $\boldsymbol{d}\left(\boldsymbol{x} \mathbf{1 0 ^ { - 3 }} \boldsymbol{m}\right)$ & $\boldsymbol{C}(\boldsymbol{N})$ & $\boldsymbol{d}\left(\boldsymbol{x} \mathbf{1 0}^{-3} \boldsymbol{m}\right)$ & $\boldsymbol{N} / \boldsymbol{m}$ & $\boldsymbol{x 1 0}^{-3} \boldsymbol{J}$ & $\boldsymbol{x 1 0}^{-3} \boldsymbol{J}$ \\
\hline $\mathbf{1}$ & 210,89 & 1,14 & 200,74 & 0,66 & 334,84 & 60,43 & 287,41 \\
$\mathbf{2}$ & 182,42 & 0,92 & 152,91 & 0,52 & 337,68 & 42,89 & 306,47 \\
$\mathbf{3}$ & 186,22 & 1,00 & 174,32 & 0,74 & 238,88 & 59,22 & 303,41 \\
$\mathbf{4}$ & 211,65 & 1,14 & 157,30 & 0,58 & 287,66 & 39,97 & 281,12 \\
$\mathbf{5}$ & 224,45 & 1,84 & 210,52 & 1,02 & 218,15 & 97,96 & 468,36 \\
$\mathbf{6}$ & 180,31 & 1,22 & 156,67 & 0,96 & 180,54 & 65,70 & 334,40 \\
$\mathbf{7}$ & 181,98 & 1,18 & 155,49 & 0,94 & 182,16 & 63,93 & 310,30 \\
$\mathbf{8}$ & 142,05 & 1,16 & 138,32 & 1,08 & 137,29 & 63,62 & 170,52 \\
$\mathbf{9}$ & 218,76 & 1,46 & 130,08 & 0,92 & 159,01 & 45,20 & 331,66 \\
$\mathbf{1 0}$ & 191,59 & 1,10 & 90,15 & 0,56 & 170,73 & 81,41 & 221,36 \\
$\mathbf{1 1}$ & 164,12 & 1,16 & 157,65 & 1,08 & 151,44 & 67,01 & 286,42 \\
$\mathbf{1 2}$ & 218,27 & 1,20 & 169,03 & 0,76 & 242,84 & 64,29 & 312,99 \\
$\mathbf{1 3}$ & 258,89 & 1,24 & 221,41 & 0,90 & 256,46 & 89,19 & 367,59 \\
$\mathbf{1 4}$ & 217,59 & 1,14 & 203,75 & 0,90 & 234,63 & 85,16 & 382,63 \\
$\mathbf{1 5}$ & 197,28 & 1,86 & 161,28 & 1,50 & 111,66 & 89,47 & 333,13 \\
$\mathbf{1 6}$ & 176,58 & 1,26 & 155,29 & 0,96 & 167,10 & 65,53 & 238,81 \\
$\mathbf{1 7}$ & 215,33 & 0,98 & 195,91 & 0,80 & 353,74 & 49,66 & 400,24 \\
$\mathbf{1 8}$ & 169,12 & 1,46 & 117,13 & 0,42 & 312,52 & 22,08 & 316,80 \\
$\mathbf{1 9}$ & 198,06 & 0,98 & 152,94 & 0,56 & 306,29 & 44,25 & 253,59 \\
$\mathbf{2 0}$ & 234,75 & 1,30 & 135,08 & 0,44 & 310,98 & 27,97 & 238,86 \\
\hline & & & & & & &
\end{tabular}


A TABELA 02 mostra os valores de energia absorvida para os 20 fêmures direitos utilizados no ensaio de impacto.

TABELA 02 - Energia absorvida pelos fêmures no ensaio de impacto.

\begin{tabular}{cccc}
\hline $\mathbf{N}$ & tenacidade $(\mathbf{J})$ & $\mathbf{N}$ & tenacidade $(\mathbf{J})$ \\
\hline 1 & 1,20 & 11 & 1,39 \\
2 & 0,98 & 12 & 1,04 \\
3 & 1,26 & 13 & 6,42 \\
4 & 1,42 & 14 & 1,89 \\
5 & 2,60 & 15 & 2,29 \\
6 & 5,50 & 16 & 1,80 \\
7 & 1,46 & 17 & 0,89 \\
8 & 1,58 & 18 & 3,60 \\
9 & 1,17 & 19 & 2,01 \\
10 & 1,03 & 20 & 0,83 \\
\hline
\end{tabular}

Os fêmures 6 e 13 foram eliminados do estudo por causa do alto valor de tenacidade, maior que 10 vezes o desvio padrão da amostra, sendo este o critério de eliminação de valores não representativos da população.

A TABELA 03 mostra os valores das áreas relativas ocupadas pelas fibras de colágeno com disposição transversal obtidas a partir das secções transversais dos fêmures ensaiados sob flexão e impacto.

TABELA 03 - Área relativa ocupada pelas fibras de colágeno $\left(A_{R F}\right)$ obtidas a partir das secções transversais dos fêmures ensaiados.

\begin{tabular}{|c|c|c|c|c|c|}
\hline$N$ & $A_{R F}($ flexão $)$ & $A_{R F}($ impacto $)$ & $N$ & $A_{R F}($ flexão $)$ & $A_{R F}($ impacto \\
\hline $\bar{~} 1$ & 0,2984 & 0,3374 & $\overline{111}$ & 0,2496 & (0,3044 \\
\hline 2 & 0,3030 & 0,4324 & 12 & 0,3280 & 0,3203 \\
\hline 3 & 0,2770 & 0,3495 & 13 & 0,2472 & 0,2291 \\
\hline 4 & 0,2645 & 0,3084 & 14 & 0,2845 & 0,3125 \\
\hline 5 & 0,2789 & 0,4371 & 15 & 0,2732 & 0,4165 \\
\hline 6 & 0,3213 & 0,2600 & 16 & 0,3292 & 0,2928 \\
\hline 7 & 0,2184 & 0,3049 & 17 & 0,3314 & 0,2914 \\
\hline 8 & 0,2830 & - & 18 & 0,2729 & - \\
\hline 9 & 0,2982 & 0,3661 & 19 & 0,3787 & 0,3274 \\
\hline 10 & 0,2384 & 0,3956 & 20 & 0,3371 & 0,2756 \\
\hline
\end{tabular}


Os fêmures 8 e 18 foram eliminados do estudo por terem sofrido fratura cominutiva e impossibilitado o corte da secção transversal para inclusão na lâmina histológica.

A TABELA 04 mostra a média e o desvio padrão das propriedades mecânicas e das áreas relativas ocupadas pelas fibras de colágeno dos fêmures ensaiados.

TABELA 04 - Propriedades mecânicas e microestrututural.

\begin{tabular}{lcc}
\hline & flexão & impacto \\
\hline fêmures & 20 & 16 \\
carga máxima $(\mathrm{N})$ & $199,02 \pm 27,32$ & - \\
deformação máxima $\left(\times 10^{-3} \mathrm{~m}\right)$ & $1,24 \pm 0,25$ & - \\
carga proporcional $(\mathrm{N})$ & $161,80 \pm 32,67$ & - \\
deformação proporcional $\left(\times 10^{-3} \mathrm{~m}\right)$ & $0,82 \pm 0,27$ & - \\
rigidez $\left(\mathrm{x} 10^{3} \mathrm{~N} / \mathrm{m}\right)$ & $234,73 \pm 75,07$ & - \\
resiliência $(\mathrm{J})$ & $0,061 \pm 0,0207$ & - \\
tenacidade $(\mathrm{J})$ & $0,307 \pm 0,067$ & $1,453 \pm 0,523$ \\
A $_{\mathrm{RF}}$ colágeno & $0,291 \pm 0,039$ & $0,342 \pm 0,052$ \\
\hline
\end{tabular}

A energia absorvida (tenacidade) no ensaio de impacto foi $523 \%$ maior que a energia absorvida até a ruptura (tenacidade) no ensaio de flexão (FIGURA 20, sendo que houve diferença significativa entre os dois valores $(\mathrm{p}<0,05)$.

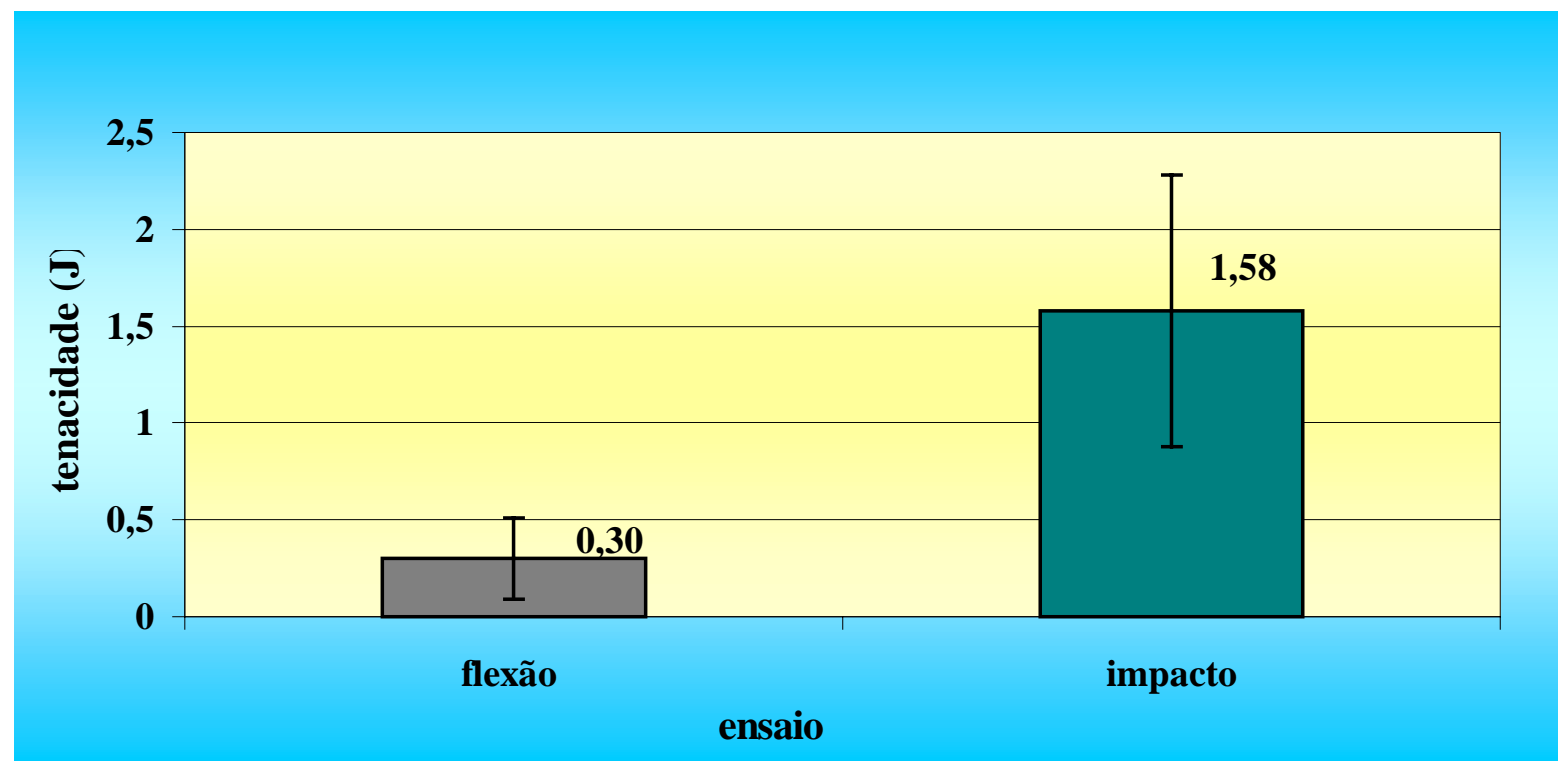

FIGURA 20 - Comparação das tenacidades obtidas nos dois ensaios. 
Através da regressão linear foram encontrados os seguintes valores TABELA 05 para as propriedades mecânicas e a estimativa de fibras de colágeno das secções transversais.

TABELA 05 - Índice de correlação linear (r) entre as propriedades mecânicas e a estimativa das fibras de colágeno transversais das secções ósseas.

\begin{tabular}{lcc}
\hline & flexão $(\mathrm{N}=20)$ & impacto $(\mathrm{N}=16)$ \\
\hline carga máxima & 0,12 & - \\
deformação máxima & $-0,19$ & - \\
carga proporcional & 0,04 & - \\
deformação proporcional & $-0,25$ & - \\
rigidez & $0,43^{*}$ & - \\
resiliência & $-0,46^{*}$ & - \\
tenacidade & $-0,06$ & 0,35 \\
\hline
\end{tabular}

* - îndice de correlação significante ( $\mathrm{p}<0,05)$.

A maior correlação positiva foi obtida para a rigidez $(r=0,43)$ e a maior correlação negativa foi obtida para a resiliência $(r=-0,46)$. No ensaio de impacto, o índice de correlação entre a tenacidade e a orientação das fibras de colágeno não foi significante. 


\section{DISCUSSÃO}

As propriedades mecânicas do osso variam não somente com a natureza da força aplicada, mas também a direção e a taxa de aplicação desta força. Materiais ideais são homogêneos e sempre se comportam da mesma maneira independente da orientação, mas os ossos mostram máximas propriedades materiais em uma orientação com o mínimo peso e carga metabólica. Eles possuem diferentes propriedades em diferentes direções, um fenômeno conhecido como anisotropia, enquanto outros materiais são isotrópicos, isto é, independente da direção da carga aplicada, suas propriedades mecânicas serão sempre as mesmas (TURNER et al., 1995). A resistência e a rigidez do osso são maiores na direção onde normalmente as cargas são aplicadas. Isto é particularmente verdade no osso cortical, onde ósteons são orientados na direção longitudinal como indícios da história de carregamento do osso (HERT et al., 1994 in EINHORN).

A diminuição da deformação sofrida pelo osso compacto ocorre à medida que o número de ósteons aumenta. Isto é explicado pela fraqueza da linha de cimento, que aumentam com o aumento do número de ósteons. A resistência à tração aumenta nos ósteons que têm fibras colágenas que percorrem longitudinalmente ou envolvem espiralmente, se comparadas a ossos que têm ósteons com fibras transversais.

O módulo de elasticidade e outras propriedades mecânicas, como módulo de cisalhamento, tensão máxima e propriedades de viscoelasticidade, dependem não somente da composição do osso - como a porcentagem de ossos compactos e esponjosos, ligação entre fibras, ligação entre fibra e matriz, porcentagem de osso haversiano e densidade óssea - mas também da estrutura óssea e forma geométrica das diferentes áreas do osso (AMTMANN, 1968). Por estas características não optamos por fazer corpos de prova para a realização deste trabalho pela riqueza de informações que o estudo do osso inteiro nos fornece. 
Os estudos mecânicos da estrutura óssea também nos fornece mais informações para o entendimento dos mecanismos de fratura. Fratura óssea pode ser causada por trauma, degeneração, fadiga ou doença. A maioria das fraturas resulta de uma combinação de diversos fatores ocorrendo simultaneamente. A quantidade de energia absorvida antes da fratura pode ser calculada medindo-se a área abaixo da curva tensão $x$ deformação. Fraturas podem ocorrer quando a energia cinética de partes sob impacto é concentrada abruptamente e convertida em trabalho que produz rápida de formação no interior do osso (RADIN et al., 1979 apud GOULD, 1993)

Fraturas ocorrem em determinados padrões devido às propriedades ósseas. Quando o osso é submetido a cargas constantes, deformações plásticas ou viscosas, causadas por tensão de cisalhamento podem ocorrer com a subsequente fratura se uma fenda aparecer e progredir. Fraturas mecânicas convencionais aceitam que uma falha ou trincamento no osso propague-se causando fratura quando a tensão na extremidade da falha alcança valores críticos que superam as forças de coesão do osso.

Os materiais sólidos incluindo o osso, possuem um grande número de defeitos microscópicos que geralmente não progridem em fraturas, a menos que a energia possível aumente esses falhas maiores. Essas falhas explicam porque a curva tensão x deformação nos ossos diferem sensivelmente em propriedades elásticas na porção inicial da curva. Para que a propagação de fraturas ocorra, a energia deve romper junções químicas e criar novas superfícies. A propagação de uma fratura necessita de menor energia para continuar do que a fratura que ainda não iniciou este processo (RADIN et al., 1979 apud GOULD, 1993)².

Quando aparece uma falha no osso, a ligação mais fraca dentro do osso irá quebrar. A ligação mais fraca para concentração de tensão são os canais haversianos, canalicular, lacunar e as linhas de cimento. Um osso quebra-se precocemente sob uma carga porque a força de tração causa grande ruptura de áreas de fácil união, deste modo causando mais deformação e fratura precoce do que irá causar uma força de compressão de igual magnitude (GOULD, 1993).

\footnotetext{
${ }^{3}$ RADIN, E. et al. (1979). Practical biomechanics for the orthopaedic surgeon. New York, John Wiley \& Sons.
} 
Para a realização dos ensaios de flexão não houve dificuldades com relação à metodologia, pelo fato do Laboratório de Bioengenharia da FMRP-USP ter experiência com ensaios estáticos de materiais biológicos. Porém na realização do ensaio de impacto houve a necessidade de adaptar o suporte às dimensões dos fêmures ensaiados, pelo fato dos acessórios da máquina de impacto serem normatizados segundo a ABNT e não possuir a flexibilidade necessária para adaptação segundo a variabilidade das dimensões dos materiais biológicos.

O ensaio de impacto também não mostrou ser um bom ensaio dinâmico para o estudo das propriedades mecânicas, devido a grande variabilidade nos resultados e dos locais de fratura, que ocorreu em diversos locais, dificultando em alguns casos a returada da peça histológica do local mais próximo da fratura. Em alguns casos houve fratura cominutiva do osso, impossibilitando a obtenção da secção transversal para estudo histológico. Mesmo em corpos de prova de materiais isotrópicos, como os metais, e de dimensões definidas, os valores de energia absorvida podem apresentar uma variação de até $10 \%$, aumentando para materiais anisotrópicos com variação nas dimensões, como os ossos inteiros. O ensaio de fadiga talvez seja o ensaio dinâmico mais recomendado por fornecer mais propriedades mecânicas e possuir um maior controle dos parâmetros do ensaio.

Os ensaios de impacto têm como vantagem a existência de uma configuração de carregamento que mais se aproxima do carregamento rápido a que estão sujeitos os ossos longos nas colisões de automóveis e pancada sofrida por qualquer pessoa exposta a pancadas repentinas, melhorando o entendimento do comportamento ósseo nessas situações, além de ser um ensaio de rápida realização. Mas para que se possa compreender melhor este mecanismo é necessário reduzir ou eliminar a influência das variáveis geométricas sobre os valores de energia absorvida e aumentar a reprodutibilidade dos locais de fratura.

Os altos valores de desvio padrão obtidos para as propriedades mecânicas devem-se ao fato do osso como foi estudado, constituir de material anisotrópico e sem uniformidade geométrica, estas propriedades influenciam principalmente no ensaio de impacto, provocando a dispersão nos resultados. Porém não objetivamos fazer corpos de prova, e estudar o osso como material, pelo fato de, com isto, perdermos a interação entre os diversos componentes microestruturais existentes ao 
longo do osso. Esta dispersão também foi observada por HERT et al. (1965), mesmo utilizando corpos de prova retirados de ossos longos bovinos, para realização dos ensaios de impacto.

A comparação da velocidade de aplicação de carga mostra que a velocidade do ensaio de flexão $(0,3 \mathrm{~mm} / \mathrm{min})$ é muito menor que a de impacto $(3,8 \mathrm{~m} / \mathrm{s})$. Isto, provavelmente, deve explicar o alto percentual de relação entre energia absorvida no impacto e na flexão $\left(\mathrm{E}_{\text {impacto }} / \mathrm{E}_{\text {flexão }}=4,23\right)$. $\mathrm{O}$ fato do osso estudado ter sido o fêmur de coelho também pode ter influenciado nos valores de alta resistência ao impacto, visto que os esforços existentes neste osso são predominantemente de flexão.

Estudos têm demonstrado a grande variabilidade das tensões nas propriedades de rigidez e energia absorvida pelos ossos, que podem ser produzidas pelo fator velocidade nos ensaios. Por exemplo, tíbias humanas podem absorver $45 \%$ mais energia quando fraturadas a taxas de deformação equivalentes ao trauma, quando comparados com ensaios onde são utilizadas baixas velocidades de aplicação de carga (BURSTEIN e FRANKEL, 1971).

Uma análise do gráfico tensão $\mathrm{x}$ deformação para o ensaio de flexão é a mais indicada por eliminar variáveis geométricas das amostras ensaiadas. Porém como foi ensaiado ossos inteiros e não corpos de prova de partes do osso, não foi possível o cálculo da deformação na flexão devido ao formato irregular do osso. Então a curva carga x deflexão foi feita para estudo das propriedades mecânicas causando dispersão, por não levar em conta as propriedades geométricas do fêmur. Uma hipótese a ser estudada é a utilização dos valores de tensão (possíveis de serem calculados) que levam em conta a geometria do fêmur e o momento de inércia da secção transversal próxima ao local de fratura, e verificar a correlação entre estes valores e a área relativa de fibras de colágeno. Com esta tentativa os valores de correlação poderiam ser comparados com a literatura da área, mesmo esta utilizando corpos de prova.

A maior correlação positiva obtida entre as propriedades mecânicas e a área de fibras de colágeno ocorreu para a rigidez $(r=0,43)$. MARTIN e BOARDMAN (1993), realizando ensaio de flexão em três pontos em corpos de prova retirados de ossos bovinos, encontraram uma correlação maior entre o "índice de fibras de colágeno dispostas longitudinalmente" e a tensão máxima $(r=0,56)$, porém além da 
diferença no tipo de osso estudado, a metodologia para o estimativa da quantidade de fibras também foi diferente, sendo para a deformação máxima a correlação encontrada não foi significante.

A resiliência apresentou a maior correlação negativa $(r=-0,46)$ significante, sendo que os outras propriedades mecânicas apresentaram baixa correlação. No ensaio de impacto, a quantidade de fibras de colágeno parece não afetar a energia absorvida no impacto, pois o índice de correlação $(r=0,35)$ não foi significante.

As duas propriedades que se correlacionaram significativamente com a orientação das fibras de colágeno são propriedades obtidas na região elástica da curva, sendo que as outras duas propriedades obtidas na região elástica, carga proporcional e deformação proporcional, não tiveram índice significativo. Há duas hipóteses que poderiam explicar este fato. A primeira é que estas duas propriedades realmente não se correlacionem com as fibras de colágeno. A segunda é a de que a dificuldade de obtenção do limite de proporcionalidade faça com que haja imprecisão na obtenção deste ponto, o que faz com que o índice obtido fique distante de uma associação entre as duas propriedades. Se a segunda hipótese for verdadeira, a orientação das fibras de colágeno tem forte associação com as propriedades da região elástica, sendo um forte determinante destas.

No nosso estudo foi calculada a estimativa das fibras de colágeno orientadas transversalmente, já que foi efetuada uma medida direta das fibras evidenciadas pela luz polarizada. Diferente de MARTIN e ISHIDA (1989) e MARTIN e BOARDMAN (1993) que calcularam o índice de fibras de colágeno dispostas longitudinalmente, pressupondo que o restante da área que não estava sendo ocupada por fibras transversais (birrefringentes), era ocupada proporcionalmente por fibras longitudinais (não birrefringentes), o que se tratando de material biológico torna-se difícil assumir esta hipótese como sendo verdadeira devido a irregularidade na disposição das fibras de colágeno e outros erros inerentes ao processo de polarização.

O próprio modelo de ASCENZI e BONUCCI (1967) recebe críticas pelo fato dos três tipos de ósteons conterem muitas fibras longitudinais, mesmo os ósteons com predominância de fibras transversais possui certa quantidade de fibras longitudinais. Outro fator que provoca discussão é a teoria de que o padrão de birrefringência muda ao longo do comprimento do osso, como também a direção do 
eixo dos ósteons também muda. Por isso não quisemos fazer uma divisão das amostras pelos tipos de ósteon, procurando somente estimar as fibras de colágeno dispostas transversalmente e tornar esta estimativa uma propriedade microestrutural do osso.

Duas críticas foram feitas ao processo de polarização por BARBOS et al. (1983). A primeira diz respeito ao contorno das lamelas que não são uniformes, mas onduladas. Então quando uma secção de $100 \mu \mathrm{m}$ de espessura é examinada, os contornos ópticos de uma lamela clara correspondem às partes externas mais proeminentes das lamelas, superdimensionando o tamanho dos ósteons. O segundo ponto a ser abordado é o aumento óptico da lamela clara devido a uma variedade de fenômenos ópticos operativos como difração, interferência e efeitos de fase. Os efeitos ópticos que aumentam a espessura da lamela clara podem ser reduzidos a um mínimo fazendo-se observações microscópicas com Nicóis parcialmente cruzados, porém isto produz uma falha na transmissão da luz.

CURREY (1959) verificou que o aumento na quantidade de ósteons aumenta a porosidade do osso, diminuindo a sua resistência à tração. Com isto, locais com poucos ósteons de grande tamanho possuem maior densidade óssea e consequentemente maior resistência à tração, porém têm sua vascularização prejudicada. Neste trabalho, Currey já estava fornecendo indícios da relação entre a orientação das fibras de colágeno e as propriedades mecânicas, mostrando que os ossos com predominância de fibras longitudinais possuíam maior resistência à tração. Porém, estes achados seriam confirmados mais tarde no trabalho clássico de ASCENZI e BONUCCI (1964) isolando ósteons e verificando suas propriedades mecânicas.

Em nosso estudo optou-se por não dividir os grupos das secções transversais segundo a classificação histológica (plexiforme, osteonal e misto) por achar que esta classificação não contribuiria para o esclarecimento da interação entre as fibras de colágeno e as propriedades mecânicas, visto que a orientação das fibras de colágeno são relacionadas com as propriedades mecânicas e uma classificação não diminuiria os achados de uma quantificação.

O fato de MARTIN e ISHIDA (1989) sugerirem que a porosidade e mineralização são menos importante, ou seja possui menor correlação, que a 
orientação das fibras de colágeno não significa que as duas primeiras devam ser descartadas do estudos microestruturais, visto que se o osso for mais poroso e menos mineralizado sua resistência mecânica tende a ser menor. Porém são os feixes de fibras de colágeno que de acordo com o tipo de carregamento (tração, compressão, cisalhamento ou esforços combinados) vão ter uma orientação, que juntamente com o mineral e água tendem a maximizar a resistência do osso nesta direção para que ele possua a menor quantidade de material possível. Pode ser dito que a lei de Wolff ocorre graças ao rearranjo das fibras de colágeno induzindo a área a sofrer formação ou reabsorção óssea, resistindo mais ao tipo de carregamento aplicado na região. 


\section{CONCLUSÕES}

1. A tenacidade no ensaio de flexão foi maior que a do ensaio de flexão em três pontos.

2. No ensaio de flexão, a rigidez $(r=0,43)$ e a resiliência $(r=-0,46)$ foram as propriedades que se correlacionaram significativamente com a orientação de fibras de colágeno.

3. No ensaio de impacto não houve correlação significativa entre a tenacidade e a orientação das fibras de colágeno. 


\section{ANEXOS}

I. Valores de carga e deflexão lidos durante os ensaios de flexão em três pontos dos 20 fêmures (pg.46-9).

II. Tabela com demonstração das análises estatísticas das comparações entre as tenacidades dos ensaios de flexão e impacto (pg.50). 


\begin{tabular}{|c|c|c|c|c|c|c|c|c|c|c|}
\hline & $F(N)$ & $\mathrm{F}(\mathrm{N})$ & $F(N)$ & $\mathrm{F}(\mathrm{N})$ & $\mathrm{F}(\mathrm{N})$ & $F(N)$ & $F(N)$ & $\mathrm{F}(\mathrm{N})$ & $F(N)$ & $F(N)$ \\
\hline def. (mm) & 1 & 2 & 3 & 4 & 5 & 6 & 7 & 8 & 9 & 10 \\
\hline 0.00 & 4.46 & 2.89 & 3.46 & 3.46 & 5.10 & 2.35 & 1.77 & 1.96 & 1.77 & 3.73 \\
\hline 0.02 & 11.01 & 9.76 & 10.10 & 8.68 & 7.36 & 4.81 & 3.24 & 2.94 & 3.04 & 6.28 \\
\hline 0.04 & 16.31 & 17.04 & 14.27 & 13.10 & 10.20 & 5.49 & 5.40 & 4.22 & 4.61 & 8.63 \\
\hline 0.06 & 21.46 & 22.61 & 18.69 & 17.76 & 13.15 & 7.26 & 7.46 & 5.40 & 5.69 & 10.89 \\
\hline 0.08 & 27.15 & 30.95 & 22.93 & 22.12 & 15.79 & 9.52 & 9.61 & 6.47 & 7.06 & 13.34 \\
\hline 0.10 & 32.35 & 37.82 & 27.81 & 26.14 & 18.84 & 11.09 & 12.46 & 7.95 & 8.44 & 15.30 \\
\hline 0.12 & 39.12 & 45.67 & 32.64 & 30.73 & 21.88 & 14.03 & 15.01 & 8.93 & 9.71 & 18.05 \\
\hline 0.14 & 44.39 & 53.02 & 38.33 & 34.04 & 25.70 & 16.19 & 17.76 & 10.01 & 10.79 & 21.39 \\
\hline 0.16 & 50.08 & 61.48 & 43.63 & 38.53 & 29.63 & 18.44 & 20.31 & 11.38 & 12.07 & 23.74 \\
\hline 0.18 & 55.33 & 73.60 & 49.34 & 43.78 & 32.67 & 21.29 & 23.45 & 12.56 & 13.44 & 26.49 \\
\hline 0.20 & 61.66 & 77.99 & 54.25 & 48.41 & 36.79 & 14.03 & 26.29 & 14.32 & 15.11 & 29.63 \\
\hline 0.22 & 67.44 & 85.15 & 57.27 & 55.30 & 40.81 & 26.68 & 28.84 & 15.99 & 16.68 & 32.18 \\
\hline 0.24 & 73.80 & 92.36 & 61.93 & 60.50 & 45.03 & 29.92 & 31.78 & 18.05 & 17.95 & 35.51 \\
\hline 0.26 & 80.25 & 99.40 & 66.44 & 67.52 & 48.66 & 33.26 & 35.02 & 20.11 & 19.33 & 38.36 \\
\hline 0.28 & 87.43 & 106.51 & 71.47 & 73.08 & 52.68 & 36.98 & 38.26 & 22.46 & 21.19 & 41.01 \\
\hline 0.30 & 93.32 & 111.93 & 76.91 & 80.05 & 57.19 & 40.61 & 41.40 & 24.53 & 23.54 & 44.24 \\
\hline 0.32 & 99.82 & 118.21 & 81.06 & 87.48 & 62.00 & 44.05 & 44.64 & 26.98 & 25.31 & 47.09 \\
\hline 0.34 & 106.98 & 125.30 & 87.19 & 94.54 & 65.63 & 47.77 & 48.56 & 29.72 & 27.47 & 50.23 \\
\hline 0.36 & 114.65 & 131.77 & 91.63 & 100.68 & \begin{tabular}{|c|}
70.14 \\
\end{tabular} & 50.82 & 52.29 & 32.47 & 30.12 & 53.56 \\
\hline 0.38 & 121.91 & 138.12 & 97.81 & $\begin{array}{ll}106.86 \\
\end{array}$ & \begin{tabular}{|c|}
74.07 \\
\end{tabular} & 55.23 & 56.60 & 35.22 & 32.47 & 56.90 \\
\hline 0.40 & 130.03 & 143.50 & 101.58 & 113.35 & 78.97 & 58.47 & 59.45 & 37.96 & 34.83 & 60.23 \\
\hline 0.42 & $\begin{array}{l}137.27 \\
\end{array}$ & 148.74 & 106.05 & \begin{tabular}{|c|}
120.59 \\
\end{tabular} & 82.99 & 62.10 & 63.37 & 40.71 & \begin{tabular}{|c|}
37.77 \\
\end{tabular} & 63.86 \\
\hline 0.44 & 146.88 & 153.23 & 111.54 & 126.72 & 87.51 & 66.41 & 67.59 & 43.65 & 41.01 & 67.30 \\
\hline 0.46 & 155.27 & 157.97 & 116.15 & \begin{tabular}{|c|}
132.12 \\
\end{tabular} & 92.21 & 70.34 & 71.42 & 46.89 & 44.73 & 70.73 \\
\hline 0.48 & 162.65 & 162.11 & 121.03 & \begin{tabular}{l|l}
137.76 \\
\end{tabular} & 96.73 & 74.75 & 74.75 & 49.44 & 48.27 & 74.36 \\
\hline 0.50 & 169.39 & 163.93 & 125.62 & 143.25 & 101.53 & 78.77 & 79.07 & 52.19 & 51.60 & 78.28 \\
\hline 0.52 & 176.87 & 152.91 & 130.40 & 148.18 & 105.46 & 82.40 & 82.89 & 55.92 & 56.31 & 91.92 \\
\hline 0.54 & 183.64 & 154.63 & 134.89 & \begin{tabular}{|c|}
156.98 \\
\end{tabular} & 109.68 & 86.52 & 87.41 & 59.55 & 60.43 & 86.52 \\
\hline 0.56 & 188.99 & 161.99 & 139.38 & \begin{tabular}{l|l}
160.96 \\
\end{tabular} & 115.27 & 91.13 & 91.23 & 62.49 & 64.26 & 90.15 \\
\hline 0.58 & 194.63 & 166.48 & 144.50 & 157.30 & 119.39 & 94.96 & 94.86 & 65.43 & 69.45 & 94.37 \\
\hline 0.60 & 198.65 & 170.55 & 149.53 & 149.65 & 124.49 & 98.79 & 99.08 & 68.77 & \begin{tabular}{|c|}
73.87 \\
\end{tabular} & 98.88 \\
\hline 0.62 & 201.96 & 174.57 & 154.24 & \begin{tabular}{|l|}
153.21 \\
\end{tabular} & 128.22 & 103.01 & 103.10 & 71.91 & 78.28 & 102.61 \\
\hline 0.64 & 203.93 & 177.44 & 158.80 & 159.90 & 133.42 & 107.42 & 107.13 & 75.44 & 82.50 & 106.93 \\
\hline 0.66 & 200.74 & 179.42 & 163.29 & \begin{tabular}{ll|}
164.10 \\
\end{tabular} & 138.12 & 111.54 & 111.15 & 78.58 & 87.41 & 111.25 \\
\hline 0.68 & 182.10 & 180.33 & 168.07 & 168.39 & 142.64 & 115.37 & 115.46 & 81.62 & 92.31 & 115.76 \\
\hline 0.70 & 180.21 & 176.24 & 173.24 & \begin{tabular}{|c|}
172.78 \\
\end{tabular} & 147.25 & 119.29 & 119.68 & 85.05 & 96.73 & 119.49 \\
\hline 0.72 & 183.01 & 171.58 & 173.39 & 174.59 & 152.15 & 123.41 & 123.80 & 87.80 & 101.34 & 124.10 \\
\hline 0.74 & 188.84 & 172.02 & 174.32 & \begin{tabular}{|c|}
186.44 \\
\end{tabular} & 156.86 & 126.65 & 127.53 & 91.04 & 106.24 & 128.71 \\
\hline 0.76 & 194.65 & 169.54 & 173.56 & 185.11 & 161.77 & 129.30 & 132.04 & 94.47 & 111.54 & 133.61 \\
\hline 0.78 & 200.76 & 168.66 & 171.82 & 190.39 & \begin{tabular}{ll|}
166.57 \\
\end{tabular} & 132.53 & 136.26 & 97.81 & 116.15 & 138.52 \\
\hline 0.80 & 203.19 & 169.88 & 172.75 & 171.90 & 171.28 & 135.67 & 140.77 & 100.85 & 120.76 & 142.54 \\
\hline 0.82 & 203.56 & 172.88 & 174.05 & 175.80 & \begin{tabular}{|c|}
177.07 \\
\end{tabular} & 139.69 & 144.89 & 103.40 & 125.47 & 147.05 \\
\hline 0.84 & 204.66 & 174.77 & 175.45 & 179.65 & \begin{tabular}{|c|}
182.17 \\
\end{tabular} & 144.40 & 148.62 & 106.93 & 130.57 & 151.37 \\
\hline 0.86 & 205.05 & 176.87 & 177.14 & 183.62 & 186.39 & 147.74 & 152.15 & 110.07 & 134.99 & 155.88 \\
\hline 0.88 & 204.34 & \begin{tabular}{|c|}
179.11 \\
\end{tabular} & 179.55 & \begin{tabular}{|c|}
187.10 \\
\end{tabular} & $\begin{array}{l}191.30 \\
\end{array}$ & 152.06 & 155.59 & 112.82 & 137.83 & 160.30 \\
\hline 0.90 & 204.17 & 181.34 & 181.51 & \begin{tabular}{l|l}
190.76 \\
\end{tabular} & 196.10 & 155.39 & 158.43 & 115.66 & 130.67 & 164.71 \\
\hline 0.92 & 203.19 & 182.42 & 183.15 & \begin{tabular}{|c|}
194.31 \\
\end{tabular} & 200.42 & 159.02 & 157.74 & 119.39 & 130.08 & 168.83 \\
\hline 0.94 & 203.19 & 181.63 & 183.94 & 198.21 & 205.13 & 159.41 & 155.49 & 122.53 & 134.89 & 173.54 \\
\hline 0.96 & 204.54 & \begin{tabular}{|c|}
175.84 \\
\end{tabular} & 184.43 & 201.62 & 208.56 & 156.67 & 154.51 & 125.67 & 139.79 & 177.46 \\
\hline 0.98 & 205.64 & 167.11 & 185.46 & 204.73 & 212.09 & 153.62 & 154.80 & 128.12 & 143.32 & 181.49 \\
\hline 1.00 & 206.23 & 164.69 & 186.22 & 207.14 & 214.54 & 151.56 & 155.98 & 131.26 & 148.62 & 185.31 \\
\hline 1.02 & 206.62 & 162.40 & 186.05 & 208.32 & 210.52 & 152.25 & 158.92 & 134.00 & 152.25 & 185.11 \\
\hline 1.04 & 204.93 & 161.10 & 181.31 & 209.71 & 199.44 & 154.80 & 162.65 & 136.46 & 156.47 & 186.39 \\
\hline 1.06 & 205.57 & 159.41 & 178.05 & 210.99 & 196.20 & 157.94 & 166.08 & 138.12 & 160.69 & 188.84 \\
\hline 1.08 & 207.09 & 159.51 & 176.26 & 211.33 & 197.67 & 160.98 & 169.12 & 138.32 & 164.42 & 191.39 \\
\hline 1.10 & 208.34 & 157.08 & 176.56 & 211.38 & 200.03 & 163.83 & 172.46 & 139.11 & 168.63 & 191.59 \\
\hline 1.12 & 209.84 & 155.10 & 176.78 & 211.43 & 201.69 & 166.28 & 175.80 & 140.68 & 172.56 & 160.20 \\
\hline 1.14 & 210.89 & 152.40 & \begin{tabular}{|c|}
176.38 \\
\end{tabular} & 211.65 & 203.56 & 169.52 & 177.86 & 141.66 & 175.70 & 134.79 \\
\hline 1.16 & 208.66 & 150.53 & 175.48 & 211.16 & 205.81 & 173.24 & 180.01 & 142.05 & 177.36 & 126.35 \\
\hline 1.18 & 206.40 & 148.70 & 174.99 & 210.38 & 207.38 & 175.30 & 181.98 & 141.56 & 180.31 & 115.86 \\
\hline 1.20 & 204.91 & 146.61 & 175.53 & 208.78 & 209.25 & 177.76 & 180.99 & 140.28 & 183.64 & 112.42 \\
\hline 1.22 & 203.26 & 144.08 & 176.04 & 206.43 & 209.93 & 180.31 & 175.60 & 131.36 & 186.39 & 108.50 \\
\hline 1.24 & 201.69 & 142.64 & 176.46 & 201.28 & 211.50 & 177.07 & 176.29 & 128.02 & 189.53 & 107.62 \\
\hline 1.26 & 198.63 & 141.63 & 177.02 & 195.78 & 212.48 & 175.70 & 177.86 & 125.57 & 192.37 & 107.32 \\
\hline 1.28 & 196.59 & 140.65 & 177.44 & 190.68 & 213.17 & 173.24 & 178.74 & 125.18 & 195.61 & 105.95 \\
\hline 1.30 & 190.71 & 139.57 & 177.24 & 187.69 & 212.98 & 168.34 & 180.50 & 124.29 & 199.34 & 105.16 \\
\hline
\end{tabular}


continuação

\begin{tabular}{|c|c|c|c|c|c|c|c|c|c|c|}
\hline & $\mathrm{F}(\mathrm{N})$ & $F(N)$ & $F(N)$ & $\mathrm{F}(\mathrm{N})$ & $\mathrm{F}(\mathrm{N})$ & $\mathrm{F}(\mathrm{N})$ & $\mathrm{F}(\mathrm{N})$ & $\mathrm{F}(\mathrm{N})$ & $\mathrm{F}(\mathrm{N})$ & $\mathrm{F}(\mathrm{N})$ \\
\hline def. $(\mathrm{mm})$ & 1 & 2 & 3 & 4 & 5 & 6 & 7 & 8 & 9 & 10 \\
\hline 1.32 & 185.19 & 138.62 & 177.34 & 185.24 & 211.11 & 166.87 & 179.33 & 108.50 & 202.87 & 104.67 \\
\hline 1.34 & 179.84 & 137.59 & 177.59 & 182.74 & 211.01 & 163.53 & 175.60 & 101.04 & 205.32 & 103.79 \\
\hline 1.36 & 176.43 & 136.11 & 177.39 & 180.60 & 211.80 & 159.31 & 168.05 & 99.77 & 208.36 & 103.10 \\
\hline 1.38 & 174.42 & 135.03 & 177.24 & 179.16 & 212.48 & 158.24 & 167.65 & 99.08 & 211.21 & 102.42 \\
\hline 1.40 & 172.26 & 133.61 & 177.41 & 177.32 & 213.37 & 158.43 & 147.44 & 98.88 & 213.66 & 101.83 \\
\hline 1.42 & 170.25 & 132.63 & 177.36 & 175.26 & 214.54 & 158.33 & 129.98 & 98.88 & 215.72 & 101.34 \\
\hline 1.44 & 168.73 & 131.43 & 177.32 & 173.54 & 215.62 & 158.92 & 126.84 & 98.10 & 217.49 & 101.14 \\
\hline 1.46 & 166.08 & 130.52 & 177.12 & 171.26 & 217.68 & 158.92 & 127.24 & 97.22 & 218.76 & 100.55 \\
\hline 1.48 & $\begin{array}{l}163.02 \\
\end{array}$ & 130.33 & 176.97 & 167.53 & 218.76 & 158.24 & 127.24 & 96.82 & 217.88 & 100.26 \\
\hline 1.50 & 160.57 & 129.69 & 176.48 & 165.00 & 219.55 & 156.47 & 127.04 & 96.14 & 212.88 & 99.87 \\
\hline 1.52 & 158.14 & 129.20 & 175.84 & 162.94 & 219.94 & 155.88 & 126.55 & 94.86 & 202.38 & 99.38 \\
\hline 1.54 & 156.05 & 128.49 & 174.81 & 160.96 & 219.45 & 156.18 & 125.86 & 94.47 & 199.24 & 99.08 \\
\hline 1.56 & 153.65 & 128.00 & 173.96 & 159.66 & 219.45 & 156.27 & 125.76 & 94.18 & 200.71 & 98.59 \\
\hline 1.58 & 151.34 & 127.60 & 172.53 & 156.32 & 219.65 & 156.86 & 125.86 & 93.88 & 201.50 & 98.30 \\
\hline 1.60 & 149.63 & 127.04 & 171.11 & 154.83 & 219.35 & 157.25 & 125.57 & 93.69 & 202.28 & 97.02 \\
\hline 1.62 & 147.81 & 126.67 & 169.96 & 152.86 & 219.84 & 157.65 & 125.18 & 93.59 & 203.56 & 96.63 \\
\hline 1.64 & 144.43 & 126.18 & 169.12 & 150.09 & 220.33 & 157.65 & 124.78 & 93.39 & 204.24 & 96.24 \\
\hline 1.66 & 142.32 & 125.54 & 168.00 & 147.20 & 220.43 & 157.65 & 124.59 & 93.39 & 205.42 & 95.45 \\
\hline 1.68 & 140.95 & 124.86 & 166.67 & 144.77 & 221.31 & 157.84 & 124.19 & 93.10 & 206.21 & 95.16 \\
\hline 1.70 & 139.33 & 124.12 & 165.54 & 142.74 & 221.61 & 158.04 & 124.00 & 92.80 & 206.70 & 94.76 \\
\hline 1.72 & 137.51 & 123.48 & 164.49 & 140.95 & 222.20 & 158.43 & 123.41 & 92.70 & 207.19 & 94.18 \\
\hline 1.74 & 135.33 & 122.65 & 163.53 & 139.69 & 222.69 & 154.12 & 121.55 & 92.41 & 207.78 & 93.98 \\
\hline 1.76 & 132.48 & 122.16 & 162.33 & 138.84 & 223.37 & 152.06 & 120.27 & 92.12 & 208.76 & 93.59 \\
\hline 1.78 & 130.62 & 121.57 & 161.47 & 138.08 & 223.37 & 151.27 & 119.09 & 92.12 & 209.25 & 93.29 \\
\hline 1.80 & \begin{tabular}{|c|}
28.17 \\
\end{tabular} & 121.10 & 160.54 & 137.09 & 223.67 & 150.39 & 118.11 & 91.92 & 209.93 & 93.10 \\
\hline 1.82 & 127.06 & 120.71 & 159.39 & 136.26 & 224.26 & 149.99 & 117.52 & 91.72 & 210.92 & 92.61 \\
\hline 1.84 & 125.18 & 119.83 & 158.60 & 135.11 & 224.45 & 149.50 & 116.64 & 91.33 & 211.50 & 92.02 \\
\hline 1.86 & 124.10 & 118.95 & 157.70 & 134.15 & 224.26 & 149.31 & 114.38 & 91.04 & 211.60 & 91.63 \\
\hline 1.88 & 123.26 & 118.46 & 156.00 & 133.37 & 224.35 & 148.92 & 112.72 & 90.55 & 211.80 & 91.04 \\
\hline 1.90 & 122.31 & 118.19 & 154.58 & 132.48 & 224.26 & 148.13 & 111.25 & 90.25 & 211.90 & 90.84 \\
\hline 1.92 & 121.40 & 117.70 & 153.33 & 131.82 & 223.67 & $\begin{array}{l}147.15 \\
\end{array}$ & 109.68 & 90.06 & 210.92 & 90.64 \\
\hline 1.94 & 121.03 & 117.13 & 152.10 & 130.99 & 222.69 & 146.17 & 108.50 & 89.47 & 208.85 & 90.25 \\
\hline 1.96 & & 116.13 & 150.95 & 130.13 & 222.00 & 144.89 & 105.26 & 89.17 & 206.40 & 90.06 \\
\hline 1.98 & & 115.66 & 150.36 & 129.05 & 221.02 & 144.40 & 103.10 & 88.78 & 204.24 & 89.96 \\
\hline 2.00 & & 115.24 & 149.58 & & 219.94 & 143.52 & 101.34 & 88.29 & 201.89 & 89.66 \\
\hline 2.02 & & 114.97 & 148.82 & & 218.86 & 142.44 & 100.55 & 87.90 & 199.54 & 89.17 \\
\hline 2.04 & & 114.51 & 148.13 & & 217.59 & 141.56 & 100.06 & 87.90 & 197.67 & 88.58 \\
\hline 2.06 & & 114.02 & 147.62 & & 216.02 & 139.79 & 99.08 & 87.11 & 195.42 & 88.39 \\
\hline 2.08 & & 113.67 & 146.83 & & 213.86 & 137.93 & 98.79 & 86.92 & 192.67 & 88.29 \\
\hline 2.10 & & 113.35 & 145.87 & & 212.68 & 134.79 & 98.10 & 86.43 & 190.12 & 88.00 \\
\hline 2.12 & & 112.86 & 145.24 & & 211.50 & 133.22 & 97.71 & 86.13 & 188.45 & 87.60 \\
\hline 2.14 & & 112.45 & 143.99 & & 210.33 & 130.67 & 97.32 & & 184.82 & 87.41 \\
\hline 2.16 & & 112.08 & 142.69 & & 208.27 & $\begin{array}{l}129.59 \\
\end{array}$ & 96.53 & & 182.37 & 87.01 \\
\hline 2.18 & & 111.61 & & & 206.89 & 128.22 & 95.45 & & 180.11 & 86.62 \\
\hline 2.20 & & 111.39 & & & 204.73 & 127.43 & 94.67 & & 176.87 & 86.23 \\
\hline 2.22 & & 111.17 & & & 203.17 & 125.86 & 94.08 & & 174.81 & 85.94 \\
\hline 2.24 & & 110.90 & & & 201.40 & 124.98 & 93.59 & & 172.66 & 85.45 \\
\hline 2.26 & & 110.46 & & & 199.24 & 123.80 & 93.10 & & 170.89 & 85.25 \\
\hline 2.28 & & 109.41 & & & 197.97 & 123.41 & 92.21 & & 169.12 & 84.66 \\
\hline 2.30 & & 108.74 & & & \begin{tabular}{|c|}
197.18 \\
\end{tabular} & 121.84 & 91.82 & & 167.16 & 84.37 \\
\hline 2.32 & & 108.40 & & & 196.20 & 121.35 & 90.94 & & 165.20 & 84.17 \\
\hline 2.34 & & 108.01 & & & 195.22 & 120.37 & 90.55 & & 163.53 & 83.88 \\
\hline 2.36 & & 107.79 & & & 194.04 & 119.68 & 89.86 & & 161.77 & 83.39 \\
\hline 2.38 & & 107.57 & & & 193.75 & 118.70 & 89.47 & & 160.20 & 83.19 \\
\hline 2.40 & & 104.18 & & & 191.98 & $\begin{array}{lll}117.82 \\
\end{array}$ & 89.37 & & 158.92 & 82.60 \\
\hline 2.42 & & 103.32 & & & 190.41 & 117.03 & 88.58 & & 157.55 & \\
\hline 2.44 & & & & & 189.33 & 116.35 & 88.00 & & & \\
\hline 2.46 & & & & & $\begin{array}{l}188.55 \\
\end{array}$ & \begin{tabular}{ll|}
115.27 \\
\end{tabular} & 87.60 & & & \\
\hline 2.48 & & & & & 188.06 & 114.68 & 87.11 & & & \\
\hline 2.50 & & & & & 187.37 & 113.99 & 86.62 & & & \\
\hline 2.52 & & & & & 186.88 & 113.40 & 86.13 & & & \\
\hline 2.54 & & & & & 186.39 & 112.62 & 85.74 & & & \\
\hline 2.56 & & & & & \begin{tabular}{|c|}
184.72 \\
\end{tabular} & 111.83 & 85.35 & & & \\
\hline 2.58 & & & & & \begin{tabular}{c|}
185.21 \\
\end{tabular} & 111.05 & 84.95 & & & \\
\hline 2.60 & & & & & 184.43 & 110.56 & 84.56 & & & \\
\hline 2.62 & & & & & 183.94 & 109.97 & 84.37 & & & \\
\hline 2.64 & & & & & 182.96 & 109.38 & 83.78 & & & \\
\hline 2.66 & & & & & 182.56 & 109.48 & 83.68 & & & \\
\hline 2.68 & & & & & 182.07 & 108.79 & 83.39 & & & \\
\hline 2.70 & & & & & 181.39 & 108.60 & 83.09 & & & \\
\hline 2.72 & & & & & 180.31 & 108.01 & 82.60 & & & \\
\hline
\end{tabular}




\begin{tabular}{|c|c|c|c|c|c|c|c|c|c|c|}
\hline & $F(N)$ & $F(N)$ & $F(N)$ & $\mathrm{F}(\mathrm{N})$ & $F(N)$ & $F(N)$ & $\mathrm{F}(\mathrm{N})$ & $F(N)$ & $F(N)$ & $F(N)$ \\
\hline def. $(\mathrm{mm})$ & 11 & 12 & 13 & 14 & 15 & 16 & 17 & 18 & 19 & 20 \\
\hline 0.00 & 1.86 & 1.77 & 4.91 & 1.67 & 1.77 & 4.02 & 2.45 & 4.91 & 3.92 & 4.91 \\
\hline 0.02 & 2.65 & 3.92 & 9.42 & 4.12 & 3.04 & 6.38 & 5.89 & 10.01 & 10.10 & 10.99 \\
\hline 0.04 & 3.83 & 7.65 & 13.83 & 6.67 & 4.12 & 8.53 & 11.97 & 15.60 & 15.01 & 17.27 \\
\hline 0.06 & 5.10 & 10.59 & 17.27 & 9.42 & 4.71 & 10.50 & 19.52 & 21.39 & 19.91 & 23.15 \\
\hline 0.08 & 6.38 & 14.22 & 22.07 & 12.65 & 5.49 & 12.75 & 26.49 & 27.96 & 26.49 & 29.72 \\
\hline 0.10 & 7.55 & 18.05 & 25.41 & 15.70 & 6.08 & 14.72 & 34.34 & 34.24 & 31.88 & 35.90 \\
\hline 0.12 & 8.63 & 21.78 & 30.41 & 19.03 & 7.06 & 17.17 & 40.91 & 40.52 & 38.65 & 43.16 \\
\hline 0.14 & 9.91 & 25.70 & 35.12 & 22.56 & 7.55 & 19.52 & 47.38 & 46.89 & 44.34 & 50.13 \\
\hline 0.16 & 10.89 & 30.31 & 39.24 & 25.90 & 8.34 & 22.27 & 54.84 & 54.05 & 50.82 & 56.31 \\
\hline 0.18 & 12.07 & 35.22 & 43.95 & 29.63 & 8.63 & 24.33 & 61.61 & 59.84 & 56.70 & 63.37 \\
\hline 0.20 & 13.44 & 39.14 & 48.95 & 33.75 & 8.83 & 26.88 & 69.26 & 66.61 & 63.08 & 69.75 \\
\hline 0.22 & 14.81 & 44.34 & 53.46 & 38.36 & 9.71 & 29.43 & 77.50 & 73.87 & 69.85 & 76.81 \\
\hline 0.24 & 16.48 & 48.66 & 58.57 & 42.48 & 10.50 & 32.18 & 85.84 & 79.95 & 76.62 & 82.40 \\
\hline 0.26 & 18.44 & 54.25 & 63.47 & 46.40 & 11.18 & 34.63 & 92.61 & 87.31 & 84.56 & 89.66 \\
\hline 0.28 & 20.40 & 59.64 & 68.08 & 50.23 & 11.97 & 37.38 & 100.16 & 93.49 & 92.90 & 96.33 \\
\hline 0.30 & 22.37 & 63.67 & 72.89 & 55.43 & 12.95 & 40.71 & \begin{tabular}{l|l}
106.83 \\
\end{tabular} & 99.57 & 99.67 & 103.40 \\
\hline 0.32 & 24.33 & 69.36 & 78.28 & 59.55 & 13.93 & 43.75 & 114.29 & 105.46 & 106.44 & 109.28 \\
\hline 0.34 & 26.78 & 74.56 & 83.48 & 64.35 & 14.91 & 46.70 & 121.64 & 111.93 & 113.70 & 114.97 \\
\hline 0.36 & 31.29 & 79.85 & 88.29 & 69.06 & \begin{tabular}{l|l}
15.70 \\
\end{tabular} & 49.93 & 127.24 & \begin{tabular}{ll|}
117.62 \\
\end{tabular} & \begin{tabular}{l|l}
120.27 \\
\end{tabular} & 121.55 \\
\hline 0.38 & 34.04 & 84.86 & 93.98 & 74.56 & 16.68 & 53.56 & 126.84 & \begin{tabular}{|c|}
122.63 \\
\end{tabular} & 124.10 & 127.82 \\
\hline 0.40 & 36.49 & 90.06 & 99.87 & 79.26 & 17.85 & 56.90 & 123.51 & 120.76 & 128.51 & 132.93 \\
\hline 0.42 & 39.53 & 95.84 & 104.48 & 84.86 & 19.72 & 60.33 & 128.51 & 117.13 & 133.32 & 138.42 \\
\hline 0.44 & 42.38 & 101.04 & 109.77 & 89.27 & 21.68 & 64.26 & 132.34 & \begin{tabular}{l|l}
121.74 \\
\end{tabular} & 139.01 & 135.08 \\
\hline 0.46 & 45.22 & 105.65 & 115.17 & 94.76 & 23.54 & 67.49 & 137.24 & 126.94 & 143.42 & 138.12 \\
\hline 0.48 & 48.36 & 110.75 & 120.56 & 99.28 & 25.41 & 70.83 & 141.85 & 130.08 & 149.21 & 142.64 \\
\hline 0.50 & 52.09 & 117.23 & 125.86 & 104.57 & 27.47 & 74.36 & 146.56 & 131.26 & 154.41 & 144.31 \\
\hline 0.52 & 55.52 & 122.53 & 130.67 & 109.58 & 29.33 & 77.60 & 152.06 & 130.77 & 158.33 & 142.93 \\
\hline 0.54 & 58.86 & 127.53 & 135.87 & 114.78 & 31.49 & 81.13 & 157.65 & 134.69 & $\begin{array}{l}159.71 \\
\end{array}$ & 142.74 \\
\hline 0.56 & 62.00 & 132.04 & 141.46 & 119.68 & 33.45 & 85.05 & 162.36 & 139.40 & 152.94 & 147.35 \\
\hline 0.58 & 65.92 & 137.05 & 146.95 & \begin{tabular}{|c|}
123.51 \\
\end{tabular} & 35.22 & 88.68 & \begin{tabular}{|c|}
162.55 \\
\end{tabular} & \begin{tabular}{|c|}
144.01 \\
\end{tabular} & 153.04 & 149.11 \\
\hline 0.60 & 69.45 & 142.15 & 153.33 & 129.10 & 37.77 & 93.49 & 161.96 & 148.72 & 158.33 & 155.00 \\
\hline 0.62 & 72.30 & 146.76 & 157.25 & 134.89 & 39.63 & 97.51 & \begin{tabular}{|c|}
165.59 \\
\end{tabular} & \begin{tabular}{|l|}
151.27 \\
\end{tabular} & \begin{tabular}{ll|}
163.14 \\
\end{tabular} & 160.88 \\
\hline 0.64 & 76.42 & 151.76 & 164.22 & 139.11 & 41.50 & 101.83 & 170.50 & 153.33 & 166.18 & 166.77 \\
\hline 0.66 & 80.64 & 156.57 & 169.12 & 144.60 & 44.05 & 105.07 & 174.52 & \begin{tabular}{l|l}
156.37 \\
\end{tabular} & 170.01 & 172.36 \\
\hline 0.68 & 84.46 & 159.71 & 175.40 & 149.99 & 46.11 & 108.60 & 178.84 & 160.59 & 174.42 & 169.03 \\
\hline 0.70 & 87.90 & 162.26 & 180.01 & 154.90 & 48.46 & 112.03 & 182.86 & 162.16 & 178.64 & 169.61 \\
\hline 0.72 & 90.94 & 164.81 & 185.31 & \begin{tabular}{|c|}
160.79 \\
\end{tabular} & 50.72 & 115.66 & 185.80 & 160.20 & \begin{tabular}{ll|}
182.47 \\
\end{tabular} & 173.93 \\
\hline 0.74 & 95.45 & 166.87 & 190.90 & 165.79 & 52.97 & 118.50 & 188.55 & 157.65 & 185.41 & 176.38 \\
\hline 0.76 & 99.28 & 169.03 & 196.00 & \begin{tabular}{|c|}
170.89 \\
\end{tabular} & 55.62 & 123.41 & \begin{tabular}{|c|}
191.39 \\
\end{tabular} & 142.34 & \begin{tabular}{l|l|}
187.57 \\
\end{tabular} & 178.05 \\
\hline 0.78 & 103.20 & 169.52 & 201.60 & 174.52 & 57.88 & 126.84 & 193.65 & 141.26 & 188.94 & 180.01 \\
\hline 0.80 & \begin{tabular}{|c|}
107.13 \\
\end{tabular} & 169.71 & 204.93 & 181.68 & 60.23 & 130.28 & 195.91 & 143.03 & 186.29 & 183.35 \\
\hline 0.82 & 111.25 & 172.46 & 210.42 & 186.00 & 62.88 & 133.91 & \begin{tabular}{|l|}
197.87 \\
\end{tabular} & \begin{tabular}{ll|}
144.70 \\
\end{tabular} & 186.10 & 186.78 \\
\hline 0.84 & 115.07 & 176.48 & 217.68 & \begin{tabular}{|c|}
191.49 \\
\end{tabular} & 65.73 & 137.44 & 200.12 & 145.97 & 188.25 & 190.71 \\
\hline 0.86 & 119.00 & 180.60 & 221.51 & 196.59 & 68.08 & 142.15 & 201.69 & \begin{tabular}{l|l}
149.21 \\
\end{tabular} & 190.31 & 194.92 \\
\hline 0.88 & 122.92 & 183.74 & 222.98 & 201.20 & 70.34 & 146.56 & 204.15 & 153.33 & 192.37 & 199.34 \\
\hline 0.90 & 127.43 & 186.98 & 221.41 & 203.75 & 72.89 & 149.80 & 207.58 & \begin{tabular}{l|l}
155.59 \\
\end{tabular} & 193.36 & 202.18 \\
\hline 0.92 & 132.24 & 190.51 & 204.05 & 205.03 & 75.44 & 153.04 & 210.52 & 157.74 & 193.75 & 203.75 \\
\hline 0.94 & \begin{tabular}{|c|}
135.67 \\
\end{tabular} & 195.81 & 207.19 & 205.91 & 78.38 & 155.29 & 212.29 & 160.00 & 195.42 & 206.21 \\
\hline 0.96 & 139.40 & 199.83 & 212.58 & 207.38 & 81.03 & 155.29 & 214.25 & \begin{tabular}{|l|}
161.87 \\
\end{tabular} & 196.98 & 209.54 \\
\hline 0.98 & 142.74 & 204.15 & 219.45 & 208.27 & 83.88 & 155.88 & \begin{tabular}{|l|}
215.33 \\
\end{tabular} & \begin{tabular}{|c|}
163.43 \\
\end{tabular} & 198.06 & 212.19 \\
\hline 1.00 & 146.95 & 207.48 & 225.24 & 206.30 & \begin{tabular}{|c|}
87.31 \\
\end{tabular} & 157.06 & 213.96 & \begin{tabular}{|c|}
164.81 \\
\end{tabular} & \begin{tabular}{l|l|}
192.67 \\
\end{tabular} & 213.56 \\
\hline 1.02 & 150.19 & 208.95 & 229.46 & 207.68 & 89.66 & 158.33 & 202.77 & \begin{tabular}{|c|}
163.53 \\
\end{tabular} & 193.26 & 215.43 \\
\hline 1.04 & \begin{tabular}{|c|}
153.23 \\
\end{tabular} & 204.15 & 233.38 & 210.52 & 92.90 & 160.20 & 198.36 & \begin{tabular}{l|l}
162.36 \\
\end{tabular} & $\begin{array}{l}193.75 \\
\end{array}$ & 216.51 \\
\hline 1.06 & 155.49 & 203.36 & 237.70 & 211.21 & 95.75 & 161.28 & 198.36 & 162.06 & 193.36 & 216.51 \\
\hline 1.08 & 157.65 & 205.91 & 242.11 & 211.90 & 98.69 & 160.98 & \begin{tabular}{|c|}
199.04 \\
\end{tabular} & \begin{tabular}{|c|}
161.67 \\
\end{tabular} & \begin{tabular}{|c|}
194.73 \\
\end{tabular} & 217.39 \\
\hline 1.10 & 160.20 & 208.27 & 246.23 & 213.66 & 101.93 & 161.77 & 198.16 & 161.37 & 195.71 & 218.08 \\
\hline 1.12 & \begin{tabular}{l|l}
162.55 \\
\end{tabular} & 212.48 & 249.47 & 216.02 & 105.16 & 163.04 & \begin{tabular}{|c|}
196.00 \\
\end{tabular} & 160.88 & 196.20 & 219.74 \\
\hline 1.14 & 163.43 & 215.43 & 252.61 & 217.59 & 108.40 & 164.81 & 193.36 & \begin{tabular}{|c|}
160.79 \\
\end{tabular} & \begin{tabular}{|c|}
196.49 \\
\end{tabular} & 221.02 \\
\hline 1.16 & \begin{tabular}{|l|}
164.12 \\
\end{tabular} & 216.90 & 255.06 & 209.93 & 111.25 & 166.77 & \begin{tabular}{|c|}
191.10 \\
\end{tabular} & 160.30 & $\begin{array}{l}196.10 \\
\end{array}$ & 222.39 \\
\hline 1.18 & \begin{tabular}{|l|}
163.73 \\
\end{tabular} & 218.08 & 256.43 & 209.84 & 114.68 & 169.32 & \begin{tabular}{|c|}
190.02 \\
\end{tabular} & \begin{tabular}{c|}
160.79 \\
\end{tabular} & 196.89 & 223.77 \\
\hline 1.20 & \begin{tabular}{l|l}
157.45 \\
\end{tabular} & 218.27 & 257.81 & \begin{tabular}{|l|}
212.68 \\
\end{tabular} & 118.01 & 171.77 & \begin{tabular}{|c|}
188.84 \\
\end{tabular} & \begin{tabular}{l|l}
162.26 \\
\end{tabular} & 197.48 & 225.34 \\
\hline 1.22 & 154.90 & 217.68 & 258.49 & 214.45 & 121.25 & 173.54 & 188.35 & 163.34 & 196.20 & 227.20 \\
\hline 1.24 & 153.92 & 216.80 & 258.89 & 213.47 & 124.49 & 175.80 & 188.55 & 163.93 & 194.34 & 229.75 \\
\hline 1.26 & 154.90 & 215.33 & 257.12 & 213.17 & 127.43 & 176.58 & \begin{tabular}{|c|}
189.14 \\
\end{tabular} & \begin{tabular}{l|l}
164.51 \\
\end{tabular} & 191.69 & 231.61 \\
\hline 1.28 & 154.21 & 211.90 & 255.26 & 212.58 & 130.77 & 173.74 & 189.33 & 165.20 & 191.10 & 233.77 \\
\hline 1.30 & 153.82 & 209.05 & 253.78 & \begin{tabular}{|l|}
211.11 \\
\end{tabular} & 133.61 & 172.85 & \begin{tabular}{|c|}
190.22 \\
\end{tabular} & \begin{tabular}{l|l}
164.32 \\
\end{tabular} & 191.30 & 234.75 \\
\hline
\end{tabular}


continuação

\begin{tabular}{|c|c|c|c|c|c|c|c|c|c|c|}
\hline & $\mathrm{F}(\mathrm{N})$ & $\mathrm{F}(\mathrm{N})$ & $\mathrm{F}(\mathrm{N})$ & $\mathrm{F}(\mathrm{N})$ & $\mathrm{F}(\mathrm{N})$ & $\mathrm{F}(\mathrm{N})$ & $\mathrm{F}(\mathrm{N})$ & $\mathrm{F}(\mathrm{N})$ & $\mathrm{F}(\mathrm{N})$ & $\mathrm{F}(\mathrm{N})$ \\
\hline def. (mm) & 11 & 12 & 13 & 14 & 15 & 16 & 17 & 18 & 19 & 20 \\
\hline 1.32 & 153.92 & 209.44 & 250.16 & 206.01 & 137.24 & 171.38 & 190.61 & 165.30 & 191.88 & 233.87 \\
\hline 1.34 & 154.70 & 211.21 & 247.21 & 205.52 & 141.07 & 170.40 & 191.79 & 166.38 & 192.57 & 231.91 \\
\hline 1.38 & 156.76 & 212.68 & 236.42 & 206.60 & 147.93 & 169.12 & 195.02 & 168.14 & 192.67 & 225.63 \\
\hline 1.40 & 157.84 & 212.98 & 235.05 & 206.40 & 151.47 & 168.83 & 196.00 & 168.54 & 192.77 & 222.49 \\
\hline 1.42 & 158.73 & 212.39 & 233.48 & 205.52 & 155.10 & 169.22 & 197.48 & 168.54 & 192.57 & 217.10 \\
\hline 1.46 & 157.35 & 199.63 & 228.87 & 202.87 & 161.96 & 170.60 & 199.83 & 169.12 & 190.90 & 214.45 \\
\hline 1.48 & 156.96 & 194.24 & 227.79 & 198.95 & 164.51 & 170.99 & 200.71 & 169.03 & 189.82 & 214.15 \\
\hline 1.50 & 156.76 & 188.06 & 226.51 & 196.69 & 161.28 & 170.50 & 201.11 & 168.05 & 187.67 & 212.48 \\
\hline 1.52 & 157.16 & 184.62 & 225.92 & 195.42 & 160.88 & 170.30 & 201.99 & 166.57 & 185.11 & 210.13 \\
\hline 1.54 & 156.96 & 184.04 & 225.73 & 194.04 & 163.43 & 169.91 & 202.38 & 164.32 & 183.94 & \\
\hline 1.56 & 157.25 & 183.84 & 225.63 & 193.36 & 166.48 & 168.93 & 202.87 & 161.67 & 183.45 & \\
\hline 1.66 & 153.23 & 180.11 & 224.55 & 188.45 & 176.09 & 164.61 & 201.40 & 157.16 & 183.05 & \\
\hline 1.68 & 151.76 & 179.62 & 223.67 & 187.86 & 178.35 & 163.93 & 201.11 & 157.45 & 182.47 & \\
\hline 1.70 & 149.60 & 177.46 & 222.20 & 187.17 & 180.80 & 163.73 & 200.52 & 156.96 & 181.68 & \\
\hline 1.72 & 148.23 & 176.48 & 221.51 & 186.00 & 184.04 & 163.34 & 199.63 & 156.37 & 181.09 & \\
\hline 1.74 & 146.76 & 176.68 & 219.35 & 185.02 & 186.00 & 163.04 & 198.46 & 155.59 & 180.60 & \\
\hline 1.76 & 145.58 & 176.58 & 217.19 & 184.62 & 188.35 & 162.36 & 197.08 & 155.49 & 180.41 & \\
\hline 1.78 & 143.81 & 175.89 & 216.80 & 184.13 & 190.22 & 161.87 & 195.81 & 155.59 & 180.11 & \\
\hline 1.80 & 142.25 & 175.01 & 212.78 & 183.05 & 191.59 & 160.88 & 194.04 & 155.29 & 179.92 & \\
\hline 1.82 & 141.07 & 174.23 & 211.80 & 180.99 & 195.32 & 158.92 & 191.30 & 154.12 & 178.44 & \\
\hline 1.84 & 139.60 & 174.13 & 209.25 & 179.72 & 196.59 & 157.06 & 187.96 & 152.94 & 176.48 & \\
\hline 1.86 & 137.54 & 174.23 & 207.09 & 178.74 & 197.28 & 155.68 & 185.31 & 152.06 & 175.50 & \\
\hline 2.02 & 129.39 & 170.40 & 194.92 & 171.28 & 177.07 & 144.60 & 166.87 & 141.46 & & \\
\hline 2.04 & 128.02 & 169.61 & 192.08 & 170.30 & 177.56 & & 164.91 & 139.01 & & \\
\hline 2.06 & 126.65 & 167.75 & 189.63 & 169.12 & 178.25 & & 163.63 & 137.54 & & \\
\hline 2.08 & 125.86 & 166.08 & 188.16 & 166.87 & 178.84 & & 163.24 & 137.24 & & \\
\hline 2.10 & 124.78 & & 186.29 & 164.02 & 178.64 & & 159.22 & 136.95 & & \\
\hline 2.12 & 123.80 & & 184.82 & 162.06 & 177.86 & & 156.47 & 136.65 & & \\
\hline 2.14 & 123.21 & & 181.78 & 160.10 & 177.07 & & 154.02 & 136.46 & & \\
\hline 2.16 & 122.43 & & & 157.84 & 176.78 & & 151.66 & 136.26 & & \\
\hline 2.18 & 121.64 & & & 156.37 & 176.58 & & 149.01 & 136.56 & & \\
\hline 2.20 & 120.86 & & & 155.19 & 176.48 & & 146.95 & 136.36 & & \\
\hline 2.22 & 119.98 & & & 153.62 & 175.80 & & 145.48 & 136.36 & & \\
\hline 2.24 & 119.00 & & & 152.55 & 175.40 & & 143.91 & 135.97 & & \\
\hline 2.26 & 118.11 & & & 151.47 & 175.11 & & 142.34 & 135.48 & & \\
\hline 2.28 & 117.43 & & & 150.19 & 174.72 & & 140.77 & 134.99 & & \\
\hline 2.30 & 117.03 & & & 149.21 & 174.23 & & 139.40 & 134.59 & & \\
\hline 2.32 & 116.64 & & & 148.33 & 173.83 & & 137.93 & 134.20 & & \\
\hline 2.34 & 115.95 & & & 147.05 & 172.17 & & 136.75 & 133.91 & & \\
\hline 2.36 & 115.46 & & & 145.68 & 168.73 & & 135.77 & 133.61 & & \\
\hline 2.38 & 114.88 & & & 144.40 & 168.24 & & 134.99 & 133.51 & & \\
\hline 2.40 & 113.99 & & & 142.83 & 167.55 & & 134.00 & 133.42 & & \\
\hline 2.42 & 113.40 & & & 141.56 & 166.48 & & 132.34 & & & \\
\hline 2.44 & 113.01 & & & 140.38 & 165.30 & & 130.87 & & & \\
\hline 2.46 & 112.52 & & & 139.30 & 164.32 & & 129.39 & & & \\
\hline
\end{tabular}


Teste-t: duas amostras presumindo variâncias diferentes tenacidades

\begin{tabular}{lrr}
\hline & \multicolumn{1}{c}{ flexão } & impacto \\
\hline Média & 0.3073 & 1.4538 \\
Variância & 0.0045 & 0.2735 \\
Observações & 20 & 16 \\
Hipótese da diferença & 0 & \\
gl & 15 & \\
Stat $t$ & -8.711202587 & \\
$\mathrm{P}(\mathrm{T}<=\mathrm{t})$ uni-caudal & $1.48547 \mathrm{E}-07$ & \\
$\mathrm{t}$ crítico uni-caudal & 1.753051038 & \\
$\mathrm{P}(\mathrm{T}<=\mathrm{t})$ bi-caudal & $2.97094 \mathrm{E}-07$ & \\
$\mathrm{t}$ crítico bi-caudal & 2.1315 & \\
\hline
\end{tabular}




\section{REFERÊNCIAS BIBLIOGRÁFICAS}

ANTMAN, E.; SCHMITT, H. P. (1968). The distribution of breaking strength in the human femur shaft. J. Biomechanics v.1, p.271-7.

ASCENZI, A. ;BASCHIERI, P.; BENVENUTI, A. (1990). The bending properties of single osteons. J. Biomechanics v.23, p.763-61.

ASCENZI, A. ; BONUCCI, E. (1964)- The ultimate tensile strength of single osteon. Acta anatom,. v.58, p.160-83.

ASCENZI, A. and BONUCCI, E (1967). The tensile properties of single osteons. Anat. Rec. v. 158, p.375-86.

ASCENZI, A. and BONUCCI, E (1968). The compressive properties of single osteons. Anat. Rec. v. 161, p.377-91.

BARBOS, M.P.; BIANCO, P; ASCENZI, A. (1983). Distribution of osteonic and interstitial components in the human femoral shaft with reference to structure, calcification, and mechanical properties. Acta Anat. v. 115, p.178-86.

BURSTEIN, A. H. ; FRANKEL, (1971). A standard test for laboratory animal bone. J. Biomechanics v.21, p.155-8.

CARTER, D. R. ; SPENGLER, D. M. (1978). Mechanical properties and composition of cortical bone. Clin. Orthopaed. Relat. Res. v.135, p.192-217. 
CHIAVERINI, V. (1979). Tecnologia Mecânica v.1. São Paulo, Mc Graw Hill.

CURREY, J. D. (1959). Differences in the tensile strength of bone of different histological types. J. Anat. v. 93, p.87-95.

CURREY, J. D. (1968). The adaptation of bone to stress. J. Theor. Biol. v.20, p.91106.

DELlMAN, H. D.; BROWN, E. M. (1982). Histologia Veterinária. Rio de Janeiro, Guanabara Koogan, p.51-61.

EINHORN, T. A. (1996). Biomechanics of Bone. In BILEZIKIAN, J. P.; RAISZ, L. G.; RODAN, G. A. - Principles of Bone Biology. San Diego, Academic Press.

EVANS, F. G. (1958). Relations between the microscopic structure and tensile strength of human bone. Acta anat. v. 35, p.285-301.

EVANS, F.G.; BANG, S. (1967). Differences and relationships between the physical properties and the microscopic structure of human femoral, tibial, and fibular cortical bone. Am. J. Anat. v.120, p.79-88.

EVANS, F. G.; VICENTELLI, R. (1969). Relation of collagen fiber orientation to some mechanical properties of human cortical bone. J. Biomechanics v.2, p.639.

FRASCA, P.; HARPER, R. A. ; KATZ, J. L. (1977). Collagen fiber orientation in human secondary osteons. Acta anatom. v.98, p.1-13.

GOTTESMAN, T.; HASHIN, Z. (1980). Analysis of viscoelastic behavior of bones on the basis of microstructure. J. Biomechanics v.13, p.89-96. 
GOULD, J. A. (1993). Fisioterapia na ortopedia e na medicina do esporte. São Paulo, Manole, p.3-47.

HAM, A. W. (1967). Histologia. Rio de Janeiro, Guanabara Koogan, p.361-425.

HERT, J.; FIALA, P.; PETRTYL, M. (1994). Osteon orientation of diaphysis of long bones in man. Bone v.15, p.269-77.

HËRT, J.; KUCERA, P.; VAVRA, M.; VOLENIK, V. (1965). Comparison of the mechanical properties of both primary and Haversian bone tissue. Acta anatom. v.61, p.412-23.

HORATH, L. (1995). Fundamentals of Materials Science for Technologists Properties, Testing, and Laboratory Exercises. New Jersey, Prentice-Hall. p.333-7.

JUNQUEIRA, L. C.; CARNEIRO, J. (1999). Histologia Básica. Rio de Janeiro, Guanabara Koogan, 9 ed., p. 111-28.

MARIN, J. (1962). Mechanical Behavior of Engineering Materials. New Jersey, Prentice-Hall. p. 83-103.

MARTIN R.B; BOARDMAN, D. L. (1993). The effects of collagen fiber orientation, porosity, density, and mineralization on bovine cortical bone bending properties. J. Biomechanics v.26, p.1047-54.

MARTIN R.B.; LAU, S. T.; MATHEWS, P. V., GIBSON, V. A.; STOVER, S. M. (1996). Collagen fiber organization is related to mechanical properties and remodeling in equine bone. A comparison of two methods. J. Biomechanics v.29, p.1515-21. 
MARTIN R.B; ISHIDA, J. (1989). The relative effects of collagen fiber orientation, porosity, density, and mineralization on bone strength. J. Biomechanics v. 22, p.419-26.

MELICK, R. A. e MILLER, D. R. (1966). Variations of tensile strength of human cortical bone with age. Clin. Sci. v. 30, p.243-8.

REILLY, D.; BURSTEIN, A. H. (1974) The mechanical properties of cortical bone. J. Bone Jt Surg. v.56-A, p.1001-21,.

RUSS, J. C. (1995). The image processing handbook. CRC Press.

SALTER, R. (1995). Distúrbios e lesões do sistema músculo-esquelético. Rio de Janeiro, MEDSI.

SINGH, I. (1978). The architecture of cancellous bone. J. Anat. v.127, p. 305-10.

SOUZA, S. A. (1977). Ensaios Mecânicos de Materiais Metálicos. São Paulo, Edgard Blücher, 3 ed.

TURNER, C. H.; CHANDRAN, A.; PIDAPARTI, R. M. V. (1995). The anisotropy of osteonal bone and its ultrastructural implications. Bone v.17, p.85-9.

VICENTELLI, R. ; EVANS, F. G. (1971). Relations among mechanical properties, collagen fibers, and calcification in adult human cortical bone. J. Biomechanics v.4, p.193-201. 


\section{OBRAS CONSULTADAS}

BEER, F. P.; JOHNSTON Jr., E. R. (1992). Mechanics of Materials. McGraw-Hill.

KLEINBAUM, D. G.; KUPPER, L. L.; MULLER, K. E. (1987). Applied regression analysis and other multivariable methods. Boston, PWS-Kent.

TIMOSHENKO, S (1982). Resistência dos Materiais - v. 1. São Paulo, Livros Técnicos e Científicos, p.107-40.

WONNACOTT, T. H.; WONNACOTT, R. J. (1990). Introdutory Statistics. Wiley. 